\title{
1 Human iPSC-derived cerebral organoids model features of 2 Leigh Syndrome and reveal abnormal corticogenesis
}

Alejandra I. Romero-Morales ${ }^{1}$, Anuj Rastogi ${ }^{1}$, Gabriella L. Robertson ${ }^{1}$, Megan L. Rasmussen ${ }^{1}$, Hoor Temuri', Ram Prosad Chakrabarty ${ }^{3}$, Gregory Scott McElroy ${ }^{3}$, Lawrence $\mathrm{Hsu}^{2}$, Paula M. Almonacid $^{4}$, Bryan A. Millis ${ }^{1,5}$, Navdeep S. Chande ${ }^{3,6}$, Jean-Philippe Cartailler ${ }^{2}$ and Vivian Gama $^{1,2,7}$

${ }^{1}$ Vanderbilt University, Cell and Developmental Biology, Nashville, TN.

${ }^{2}$ Vanderbilt University, Creative Data Solutions, Vanderbilt Center for Stem Cell Biology, Nashville, TN

${ }^{3}$ Northwestern University, Feinberg School of Medicine Department of Medicine Division of Pulmonary and Critical Care Medicine, Chicago, IL

${ }^{4}$ Universidad EAFIT, School of Economics and Finances, Colombia

${ }^{5}$ Vanderbilt University, Vanderbilt Biophotonics Center, Nashville, TN

${ }^{6}$ Northwestern University, Feinberg School of Medicine Department of Biochemistry and Molecular Genetics, Chicago, IL

${ }^{7}$ Vanderbilt University, Vanderbilt Brain Institute, Nashville, TN

\section{Corresponding author}

Correspondence should be addressed to:

Vivian Gama

PMB407935

$46521^{\text {st }}$ Avenue South, 4150A

Vanderbilt University

Nashville, TN 37240-7935

Tel: (615) 875-9490

vivian.gama@vanderbilt.edu

Running title: Modeling the effect of Leigh syndrome-associated mutations using human cerebral organoids 
bioRxiv preprint doi: https://doi.org/10.1101/2020.04.21.054361; this version posted March 11,2021. The copyright holder for this preprint (which was not certified by peer review) is the author/funder, who has granted bioRxiv a license to display the preprint in perpetuity. It is made available under aCC-BY-NC-ND 4.0 International license.

50 Keywords: Leigh syndrome, stem cells, glycolysis, oxidative phosphorylation, mitochondria, 51 neural precursor cells, neural rosettes, brain organoids

52 


\section{Summary}

54 Leigh syndrome (LS) is a rare, inherited neurometabolic disorder that presents with bilateral

55 brain lesions, caused by defects in the mitochondrial respiratory chain and associated nuclear-

56 encoded proteins. We generated iPSCs from three available LS fibroblast lines and identified,

57 through whole exome and mitochondrial sequencing, unreported mutations in pyruvate

58 dehydrogenase (GM0372, PDH; GM13411, MT-ATP6/PDH) and dihydrolipoyl dehydrogenase

59 (GM01503, DLD). LS derived cell lines were viable and able to differentiate into key progenitor

60 populations, but we identified several abnormalities in three-dimensional differentiation models

61 of brain development. LS-derived cerebral organoids showed defects in neural epithelial bud

62 generation, reduced size, and loss of cortical architecture at 100 days. The MT-ATP6/PDH line

63 produced organoid neural progenitor cells with an abnormal mitochondrial morphology

64 characterized by fragmentation and disorganization and demonstrated an increased generation

65 of astrocytes. These studies aim to provide a comprehensive phenotypic characterization of

66 available patient-derived cell lines that could be used as LS model systems.

67 


\section{Introduction}

Leigh syndrome (LS), or sub-acute necrotizing encephalomyelopathy, is an inherited neurometabolic disorder that affects the central nervous system (CNS) (Baertling et al., 2014; Gerards et al., 2016; Leigh, 1951; Sorbi and Blass, 1982). LS is a rare, progressive, early-onset disease with a prevalence of 1 in 40,000 live births (Lake et al., 2016). The pathologic features of LS are focal, bilateral lesions in one or more areas of the CNS, including the brainstem, thalamus, basal ganglia, cerebellum, and spinal cord. The most common underlying cause is defective oxidative phosphorylation (OXPHOS), due to mutations in genes encoding complexes of the mitochondrial respiratory chain (Baertling et al., 2014; Lake et al., 2015, 2016). The LS phenotype caused by mitochondrial-encoded gene mutations can be rescued by mitochondrial replacement, highlighting the importance of this organelle in LS disease progression (Ma et al., 79 2015).

The availability of animal models and brain tissue from biopsies has provided critical insight into this disease. However, our understanding of the etiology and pathology of complex neurological diseases like LS would benefit from human-derived platforms such as an induced cells into induced pluripotent stem cells (iPSCs), followed by differentiation into specific lineages has become a useful tool for complex disease modeling (Kelava and Lancaster, 2016; Di Lullo and Kriegstein, 2017). In the context of LS, iPSCs have been successfully generated from

87 patients with mutations in Mitochondrially Encoded ATP Synthase Membrane Subunit 6 (MTATP6) (Galera-Monge et al., 2016; Grace et al., 2019; Lorenz et al., 2017; Ma et al., 2015), Mitochondrially Encoded NADH:Ubiquinone Oxidoreductase Core Subunit 3 (MT-ND3) subunit 90 (Hattori et al., 2016) and the nuclear-encoded gene Surfeit locus protein 1 (SURF1) (Inak et al., 91 2019). These iPSC-model systems have been proposed for drug discovery (Inak et al., 2017;

92 Lorenz et al., 2017) as well as testing platforms for potential metabolic rescue treatments (Ma et 93 al., 2015). 
Many studies have used LS patient fibroblasts commercially available at the Coriell Institute. This repository provides scientists around the world with resources for cell and genetic research. Here we report our findings on the genomic and phenotypic characterization of iPSCs

97 derived from three LS fibroblast lines available at Coriell. Whole exome and mitochondrial sequencing revealed previously unidentified mutations in these patient-derived cell lines. While

99 these LS mutations had no effects on pluripotency, trilineage differentiation, or apoptotic sensitivity, three-dimensional differentiation into neural rosettes and cerebral organoids resulted in severe abnormalities. LS-iPSC-derived 100-day cerebral organoids showed decreased size as well as defects in the generation of neural epithelial buds. Corticogenesis was impaired in all LS mutant cell lines. MT-ATP6/PDH showed a decrease in NPC and cortical plate markers at day 30, while DLD and PDH mutants showed a reduction of the upper layer markers SATB2, BRN2, and CUX1 at day 100. These results point to aberrant corticogenesis as a driver of LS pathogenesis and demonstrate the utility of iPSC-derived systems to recapitulate CNS phenotypes and to test potential strategies to restore neurogenesis in LS.

\section{Results}

\section{Genomic characterization of Leigh syndrome fibroblasts.}

Due to the limited genomic information available for the three cell lines, we performed

112 whole-exome sequencing (WES) and mitochondrial sequencing of the fibroblasts prior to 113 reprogramming (Figure $1 \mathrm{~A}-\mathrm{C}$ ). Targeted analysis of the genes associated with Leigh syndrome

114 (Lake et al., 2016) revealed a loss of function insertion/deletion (indel) frameshift in pyruvate 115 dehydrogenase complex (PDHc) E1 alpha 1 subunit or pyruvate dehydrogenase (PDHA1, 116 c.79delC, p.Arg27fs) in the cell lines GM03672 and GM13411. A single-nucleotide 117 polymorphism (SNP) in the PDHc E3 subunit or dihydrolipoyl dehydrogenase (DLD, c.100A >G, 118 p.Thr34Ala) was identified in GM01503 (Table S1). In addition to being part of the PDHc, DLD is 119 also a component of the a-ketoglutarate and branched-chain a-ketoacid dehydrogenase 
120

121

122

123

124

125

126

127

128

129

130

131

132

133

134

135

136

137

138

139

140

141

142

143

144

complexes (Craigen, 1996). Despite the lack of genomic data, dysfunction of the PDH complex had been previously suggested in GM03672 and GM01503 (Hinman et al., 1989; Huh et al., 1990; Sorbi and Blass, 1982) as the main driver of the disease in these patients. To our knowledge, mutations in the nuclear genome of GM13411 have not been reported to date.

Mitochondrial sequencing identified several SNPs in all of the cell lines (Figure 1D). A loss of function SNP in the MT-ATP6 gene was identified in the GM13411 line. These mutations were reported in the original clinical case (Pastores et al., 1994). The authors described the T to G transition at the 8993 position that results in the substitution of a highly conserved leucine residue for an arginine (L156R). MT-ATP6 is part of the F0 domain of ATP synthase that functions as a proton channel. The L156R substitution prevents the induction of c-ring rotation, resulting in decreased ATP synthesis (Uittenbogaard et al., 2018). Heteroplasmic analysis of fibroblasts showed a $92 \%$ frequency of this mutation in the cell population, which is consistent with previous reports (Galera-Monge et al., 2016; lyer et al., 2012; Pastores et al., 1994).

\section{Characterization of iPSCs derived from commercially available Leigh syndrome} fibroblasts.

Metabolic remodeling is a crucial step toward reprogramming somatic cells into iPSCs (Mathieu and Ruohola-Baker, 2017; Panopoulos et al., 2012; Rasmussen and Gama, 2020; Rastogi et al., 2019; Wu et al., 2016). Reprogramming of fibroblasts was performed as previously described (Takahashi et al., 2007) (Figure S1A); we generated iPSCs from a healthy age-matched control and the three LS cell lines. Pluripotency was evaluated using the microarray-based analysis PluriTest (Müller et al., 2011). All three LS cell lines showed a high pluripotency score and a low novelty score (Figure S1B-C), congruent with the transcriptional profile of pluripotent stem cells. Moreover, all the reprogrammed cells expressed the pluripotent markers NANOG and OCT4 (Figure S1D) and had a normal karyotype (Figure S1E) 
To assess the ability of the LS and control cell lines to differentiate into the three germ layers, we performed trilineage differentiation. Commitment into ectodermal fate was evaluated by immunofluorescence staining of the marker PAX6 (Figure 2A), as well as the mRNA expression of the genes GATA3 and PAX6 (Figure 2B). The endoderm lineage was assessed by protein expression of the marker SOX17 (Figure 2C) and by qPCR with the expression of the genes CDX2 and SOX17 (Figure 2D). The PDH mutant cell line showed increased expression of the endodermal gene SOX17 (Figure 2D) compared to control and the other LS cell lines.

152 Clinical data available from the patient with the PDH mutation showed elevated blood pyruvate 153 levels. High concentrations of pyruvate have been shown to potentiate the differentiation of 154 human embryonic stem cells (hESCs) into endodermal and mesodermal lineages while suppressing the expression of ectodermal markers in a lineage-specific fashion (Song et al., 2019). Finally, mesodermal lineage was confirmed by the staining of the protein markers

157 Brachyury and CXCR4 (Figure 2E) and the expression of the genes TBXT and NCAM (Figure 2F).

Two-dimensional neural differentiation is not affected by Leigh syndrome-associated mutations.

To determine if the LS mutations impact the commitment and development of the neural lineage, neural progenitor cells (NPCs) were generated by a dual SMAD inhibition protocol 164 (Chambers et al., 2009) (Figure 3A). NPCs showed the expected expression of the neural 165 markers PAX6, NESTIN, and SOX2 (Figure 3B), with no differences between the protein 166 expression of the LS cell lines and control (Figure S2A). The multipotent capacity of NPCs to 167 generate the three basic neural lineages (neurons, astrocytes, and oligodendrocytes) was 168 evaluated using standard protocols (Chambers et al., 2009; TCW et al., 2017; Vescovi and 169 Snyder, 1999). Immunostaining showed $\beta 3$ TUBULIN-positive neurons, OLIG2-positive 170 oligodendrocytes, and S100ß-positive astrocytes (Figure 3C). Thus, LS NPCs constitute a 
171 multipotent population capable of differentiation into the main cellular populations of the nervous

172 system.

173 Considering that neural cell death is a hallmark of LS, we performed a cell viability assay to 174 investigate the sensitivity of the LS derived NPCs to different apoptotic stimuli (Figure S2B).

175 Treatment with DNA damaging agents etoposide and neocarzinostatin, as well as the 176 microtubule depolymerizing agent nocodazole, did not show increased sensitivity to cell death in

177 LS NPCs compared to control. To evaluate the susceptibility of the NPCs to mitochondrial 178 damage, we treated these cells with the mitochondrial oxidative phosphorylation uncoupler, 179 CCCP. No difference was observed in the viability of the LS NPCs compared to control-treated 180 with this mitochondrial toxicant.

Mitochondria in murine NPCs form an elongated network (Khacho et al., 2016) which fragments as cells differentiate. Characterization of the mitochondrial network using structured illumination microscopy (SIM) showed no major morphological changes in LS NPCs (Figure 3D and Figure S3). Thus, LS mutations do not affect the capacity of the NPCs to further differentiate into the three neural lineages, do not affect the viability of the NPCs when exposed the mitochondrial network in these cells.

\section{LS mutations cause differential accumulation of metabolites in neuralized embryoid} bodies.

193 showed an abnormal generation of neural lineages in vitro using two-dimensional culture 194 systems. SURF1 mutations caused impaired neurogenesis in cerebral organoids (Inak et al., 195 2019). Therefore, we investigated the effects of the PDH, DLD, and MT-ATP6/PDH LS 
described previously (Lancaster and Knoblich, 2014; Romero-Morales et al., 2019). Most of these 3D neural systems start with the formation of neuralized embryoid bodies (EBs). EBs are generated from a single cell suspension (Itskovitz-Eldor et al., 2000) plated in ultra-low attachment microwells with neural induction media (Figure 4A). EB diameter was measured on day 5 before plating on Matrigel-coated imaging plates. All three LS mutant lines showed an increase in their diameter compared to control (Figure 4B, PDH vs Control \& DLD vs Control: $p<0.0001$, MT-ATP6/PDH vs Control: $p=0.0209)$.

We then measured metabolite levels in EBs derived from LS cell lines using LC-MS-based metabolomics (Table S2). Several pathways were found to be potentially altered in the LS EBs compared to controls (Figure 4C and Table S3). These include central carbon metabolism (for example glycolytic intermediates like Fructose 2,6-bisphosphate (f2,6p) and tricarboxylic acid cycle (TCA) intermediates like citrate seem to be consistently enriched), glutathione metabolism, serine metabolism, cysteine metabolism, and nucleotide metabolism. Dihydroorotate, lactate, and aspartate are metabolites that were altered in the setting of electron transport chain (ETC) inhibition, and there is evidence of a trend towards the enrichment of

212 dihydroorotate, lactate, and aspartate compared to control. There also appears to be an enrichment of the NAD pool. These results suggest that LS mutations result in differential changes in metabolite concentrations, which may cause downstream changes in gene expression or cellular function.

\section{Neural rosettes derived from Leigh syndrome iPSCs show morphological differences.}

To investigate the effects of LS-associated mutations in the early stages of CNS

219 development, we generated neural rosettes using EBs grown in the presence of SMAD inhibitor 220 media (Figure 5A) (Elkabetz et al., 2008; Zhang et al., 2001). These structures have previously 221 been established to recapitulate the early neural tube formation stage of development (Elkabetz 222 et al., 2008; Wilson and Stice, 2006). 
Neural rosettes were stained with the tight junction marker ZO-1 (Elkabetz et al., 2008; Hríbková et al., 2018) and the centrosomal marker CDK5RAP2 (Figure 5B). Quantification of

225 the number of neural rosettes per field of view showed a reduction in the counts of these 226 structures in the DLD mutant compared to controls (Figure $5 \mathrm{C}, \mathrm{p}<0.001$ ). Lumen area 227 quantification showed an increase in the PDH and MT-ATP6/PDH mutants, while the DLD 228 mutant line showed a decrease in their area relative to controls (Figure 5D). The neural rosettes 229 obtained from all cell lines followed the expected formation sequence described previously 230 (Hríbková et al., 2018). The polymerization of a-tubulin and the generation of the ZO-1 ring at 231 the apical region of the rosettes are conserved in the LS mutants. Increased neural rosette 232 lumen size has previously been associated with TGF $\beta$ pathway activation (Medelnik et al., 233 2018), Notch and SHH pathway activation, and WNT inhibition (Elkabetz et al., 2008). Large rosette formation has been previously shown to be a consequence of apical domain opening and expansion rather than a process dependent on cell proliferation (Medelnik et al., 2018).

\section{Leigh syndrome-associated mutations disrupt corticogenesis in cerebral organoids.}

To investigate the effects of these mutations during corticogenesis, we generated cerebral organoids from LS iPSCs (Figure 6A). Differences between the cell lines became apparent as early as the neuroepithelial bud expansion phase. After Matrigel embedding, the MT-ATP6/PDH mutant cell line showed poor budding with large areas of non-neuroepithelial cells (Figure S4A).

242 Defective organoid formation in this cell line was significantly higher than control and the other 243 two LS cell lines (Figure S4B). A previous report showed that when iPSCs generated from 244 fibroblasts harboring the same T8993G mitochondrial mutation were differentiated into EBs, 245 there was rapid regression and death after 7 days in suspension, while the monolayer culture 246 did not show obvious deficits in cell growth (Grace et al., 2019). Given the fact the 247 neuroectoderm expansion phase happens during days 7-10, the degeneration of the MT248 ATP6/PDH organoids after embedding may recapitulate these previously reported observations. 
Higher metabolic requirements have been shown to be associated with NPC proliferation and migration in three-dimensional scaffolds and development (Fang et al., 2020; Homem et al., 2015). As the PDH mutant line did not show this particular phenotype during the expansion of

252 the neural epithelium, the presence of the additional mitochondrial mutation in the MTATP6/PDH line and the metabolic burden generated by the double mutation may be the reason 254 for the reduction of organoid formation efficiency.

Cerebral organoid growth was tracked for 100 days (Figure 6B). Growth differences in the average diameter of the organoids become significant at day 80 between control and the PDH mutant line. At days 90 and 100, organoids derived from all LS cell lines were significantly smaller than the controls. Phenotypic information available for the patient from which the PDH mutant cell line was derived indicates that this particular patient presented with microcephaly. Hence, we were able to mimic an aspect of the patient phenotype in vitro using the cerebral organoid model system.

To assess the effect of the LS mutations during the first stages of corticogenesis, day 30 organoids were sectioned and stained for the ventricular zone (VZ), subventricular zone (sVZ), 264 and cortical plate (CP) markers (Figure 6C). As expected, based on the defective neuroepithelial expansion, MT-ATP6/PDH organoids showed a significant reduction in the number of cells that stained positive for the NPC markers PAX6 and NESTIN, as well as the intermediate progenitor marker TBR2 (Figure 6D). In addition to these findings, the overall architecture in MT-ATP6/PDH organoids was compromised. There were few to no ventricle-like structures present and the foci of PAX6+ cells were not organized in the expected radial pattern.

271 positive for the glycoprotein REELIN (Lancaster et al., 2017). Cells positive for this marker were

272 identified in superficial regions of control, PDH, and DLD organoids, while none were observed

273 in the MT-ATP6/PDH organoids (Figure 6E). Early born neurons at this time point are expected

274 to migrate into the CP that will later give rise to the deep cortical layers (Camp et al., 2015). 
275

276

277

278

279

280

281

282

283

284

285

286

287

288

289

290

291

292

293

294

295

296

297

298

299

CTIP2+ and TBR1 + cells were observed in control, PDH, and DLD organoids but absent in MTATP6/PDH organoids, demonstrating once again a profound impairment in the early stages of corticogenesis when both MT-ATP6 and PDH mutations are present.

Mitochondrial morphology was evaluated in the VZ NPCs of the cerebral organoids. Cells positive for NPC marker SOX2+ demonstrated elongated mitochondrial networks that extend radially from the ventricle-like lumen (Figure 6F). This observation is consistent with what has been previously reported in SOX2+ cells in the developing mouse cortex (Khacho et al., 2016). DLD mutant organoid NPCs showed a fragmented mitochondrial network in comparison with control and PDH. As mentioned earlier, the stereotypical arrangement of the VZ was compromised in most MT-ATP6/PDH organoids. In the few areas where ventricle-like structures were identified with a conserved SOX $2+V Z$, the mitochondrial network seemed more fragmented and aggregated. This morphology was also observed in the clusters of SOX2+ cells that were scattered throughout the organoid.

In order to assess the proper cortical layer fate specification during normal cortical development, we grew the cerebral organoids until day 100 and probed for upper cortical layer markers (Figure 7A) (Florio and Huttner, 2014; Lui et al., 2011; Saito et al., 2011). Late-born superficial layer markers CUX1, BRN2, and SATB2 (layers II, III, and IV, respectively) were reduced in PDH and DLD organoids and were absent in MT-ATP6/PDH organoids (Figure 7BD). CTIP2+ cells were also reduced in PDH and DLD organoids (Figure 7B-C). Interestingly, at day 100, few PAX6+ cells were observed in PDH and DLD organoids, whereas in MTATP6/PDH organoids they were present. The reduction in the number and variety of cell types found in PDH and DLD may explain the decrease in the diameter of the organoids derived from these cell lines (Figure 6B).

Compared to controls, LS cerebral organoids showed increased staining for the astrocyte marker $S 100 \beta$ at day 100 (Figure $7 \mathrm{C}$ ). The decrease in the diversity of neuronal cell types and the increase in the presence of $S 100 \beta+$ cells may suggest a switch to astrocyte fate during 
cortical development in LS. Clinical data from LS patients include marked gliosis as part of the characteristic findings (Lake et al., 2015). While this marked gliosis is potentially associated with a reactive process secondary to neuronal damage, an intriguing alternate possibility is that progenitor cells may have an increased propensity to differentiate down the astrocyte lineage due to LS-causative mutations. Previous studies have shown that reactive astrocytes acquire molecular hallmarks of radial glial cells. It was also shown through genetic fate mapping that mature astroglial cells can dedifferentiate and resume proliferation (Robel et al., 2009, 2011). Thus, the phenotypes uncovered here could either reflect that chronic metabolic stress induced by Leigh syndrome mutations activates a brain injury response, or that the inhibition of mitochondrial metabolism in neural progenitor cells could cause defects in lineage selection.

We then explored the changes in metabolites in Day 40 organoids from control and LS samples (Figure S5). From the top 10 metabolites identified, the organic osmolyte betaine was increased in the control compared to the DLD and PDH samples, and the quaternary amine carnitine was increased in the control compared with all LS samples. L-Carnitine is essential for the transport of long-chain fatty acids into mitochondria for degradation by $\beta$-oxidation (Jernberg et al., 2017). Carnitine concentration in the brain increases during gestation (Nakano et al., 1989) and has been reported as a therapeutic option for children affected by metabolic diseases. Moreover, this compound has been shown to decrease oxidative stress, improve brain energy status, and prevent neuronal cell death in animal models of brain injury and ischemia (Ferreira and McKenna, 2017).

Pseudouridine, an isomer of uridine and the most abundant RNA modification, was decreased in DLD organoids. Pseudouridine and pseudouridine synthases (Pus) have been associated with regulating neuronal functions (Angelova et al., 2018). Specifically, Pus3 has been implicated in neural development (Diez-Roux et al., 2011). A truncated form of Pus3 accompanied with reduced levels of pseudouridine in tRNA has been identified in patients with intellectual disabilities (Shaheen et al., 2016). 
High lactate was identified in both PDH and MT-ATP6/PDH organoids, correlating with the available clinical information that both patients presented elevated lactic acid in the blood (Table 1). Lactic acid accumulation in blood and cerebrospinal fluid is the key clinical indicator for LS diagnosis and is particularly expected in the setting of PDH dysfunction (Miyabayashi et al., 1985). Also, in these two lines, the metabolite proline was elevated. High levels of proline have been associated with negative effects in brain function by interference in glutamatergic neurotransmission (Gogos et al., 1999; Vorstman et al., 2009). In addition, hydroxyphenyllactic acid was elevated in PDH mutant organoids. High levels of this metabolite have been reported in association with high lactate and pyruvate in pediatric lactic acidosis in patients with PDHc deficiency (Stern, 1994). Not surprisingly, in the MT-ATP6/PDH mutant organoids, pyruvate was also increased, correlating with the lactic acidosis expected in the organoids based on the patient phenotypes and the presence of the PDH mutation that hinders flux from pyruvate into the TCA cycle through acetyl-CoA.

Besides the previously mentioned metabolites, MT-ATP6/PDH mutant organoids presented increased levels of choline, cytidine, and leucine. Choline is a crucial metabolite for normal CNS pregnancy (Zeisel, 2006). It has also been shown to increase cell proliferation and decrease apoptosis in fetal rat hippocampal progenitor cells (Albright et al., 1999b, 1999a; Zeisel and Niculescu, 2006). Choline is also crucial for the production of the neurotransmitter acetylcholine, the sphingolipid sphingomyelin, and myelin (Oshida et al., 2003). Concomitantly, cytidine is used with choline for the generation of cytidine-5-diphosphocholine, a crucial intermediate in the

348 biosynthesis of the cell membrane phospholipids phosphatidylcholine and 349 phosphatidylethanolamine (Cansev, 2006; Rema et al., 2008). Increased abundance of the 350 branched-chain amino acid leucine has been associated with the metabolic illness maple syrup 351 urine disease and can be extremely neurotoxic (Bridi et al., 2005; García-Cazorla et al., 2014). 352 This amino acid is considered ketogenic as its end products can enter the TCA cycle for energy 
generation or act as precursors for lipogenesis and ketone body production (Manoli and

354 Venditti, 2016).

Considering all the aforementioned findings, the cerebral organoid system emerges as a promising model for the study of the effects of LS associated mutations in brain development and the effects of metabolic impairment during corticogenesis.

\section{Discussion}

Inborn errors of metabolism are rare genetic disorders resulting from defects in metabolic pathways (Agana et al., 2018; Das et al., 2010). Mitochondrial diseases are the most common group of inherited metabolic disorders and are among the most common forms of inherited neurological disorders (Gorman et al., 2016). These illnesses are challenging not only at the time of diagnosis but also during their medical evolution, as they involve multiple organ systems and there are limited therapeutic options (Grier et al., 2018; Parikh et al., 2017; Schaefer et al., 2019).

Leigh syndrome is one of these rare inherited neurometabolic diseases, with more than 75 have been reported (Finsterer, 2008; Lake et al., 2016). As it is a highly heterogeneous disease,

371 the establishment of animal and in vitro models has been challenging and limited to only select 372 mutations. The few animal models available have been utilized for the development of

373 therapeutic approaches with mixed results. Gene editing using adeno-associated virus in

374 Ndufs4-/- mice has shown partial rescue of the phenotype (Di Meo et al., 2017).

375 Supplementation of nicotinamide riboside to Sco2-/- mice showed improvement of the 376 respiratory chain defect and increased exercise tolerance due to improved mitochondrial 377 biogenesis (Cerutti et al., 2014). Hypoxia and low oxygen availability in the brain have also been 
shown to increase the life span and improve neurological findings in Ndufs4-/- mice (Ferrari et al., 2017; Jain et al., 2016, 2019).

Molecular testing and prenatal diagnosis of respiratory chain disorders using skin fibroblasts and muscle biopsies for diagnostic and research purposes are becoming mainstream procedures (Baertling et al., 2014; Calvo et al., 2006, 2012; Schubert and Vilarinho, 2020). Nevertheless, heteroplasmy in mitochondrial DNA among tissues can cause less pronounced or absent phenotypes in cultured cells (Baertling et al., 2014). Here we report the characterization and the subsequent generation of brain organoids from three commercially available Leigh syndrome fibroblast cell lines and an age-matched control.

Three-dimensional differentiation generates higher numbers of NPCs and more mature neurons than two-dimensional differentiation (Chandrasekaran et al., 2017; Di Lullo and Kriegstein, 2017; Muratore et al., 2014; Paşca et al., 2015) in part due to an improved spatial cellular environment that influences cell fate specification. Tissue architecture, mechanical cues, cell-to-cell communication (Pampaloni et al., 2007), nutrient accessibility, oxygen tension, as well as morphogen gradients characteristic of 3D systems (Tibbitt and Anseth, 2012) aid to recapitulate the development of the central nervous system (CNS) up to approximately 16 weeks post-fertilization (Camp et al., 2015; Paşca et al., 2015). We observed that all the LS cerebral organoids failed to thrive at different time points. Although organoid development initially appeared normal in cell lines with nuclear-encoded LS mutations, at later time points, the overall diameter decreased, presumably due to failure to generate upper-layer neurons. This reduction of late-born neurons may be due to the overall reduction in the PAX6+ NPCs in both PDH and DLD compared to controls. Interestingly, PDH cerebral organoids displayed arrested growth very early on, correlating with the microcephaly observed in the source patient.

The increase in the glial-specific marker S100ß in DLD and MT-ATP6/PDH organoids could also correlate with the observation that gliosis is a common clinical finding in LS patients (Baertling et al., 2014, 2016; Schubert and Vilarinho, 2020). The formation of lesions in LS has 
404

405

406

407

408

409

410

411

412

413

414

415

416

417

418

419

420

421

422

423

424

425

426

427

428

429 been described as the result of OXPHOS dysfunction and subsequent ATP depletion. Neuronal dysfunction is suspected to trigger chronic gliosis (Baertling et al., 2016). In patients, the gliosis phenotype can be accompanied by vascular hypertrophy and production of excess ROS, which increases neuronal damage (Lake et al., 2015). However, due to the lack of vascularization in the organoid model, replicating the vascular abnormalities associated with LS is not feasible in this system.

The profound dysregulation of corticogenesis in the double mutant MT-ATP6/PDH may suggest that some pregnancies harboring LS-causing mutations may not be viable, which could lead to an underestimation of the prevalence of the disease in the population (Feeney et al., 2019). Prenatal genetic evaluation is now being performed for cases where there is a known risk for mitochondrial mutations (Craven et al., 2017; White et al., 1999). This testing can be performed as early as $10-12$ weeks post conception and is usually requested if there is a history of a previously affected child or first-degree relative (Nesbitt et al., 2014). Interpretation of these tests is challenging in the case of mitochondrial mutations due to heteroplasmy; the biopsied tissues may exhibit a different mutational burden compared with other fetal tissues (Ferlin et al., 1997; Harding et al., 1992; Nesbitt et al., 2014; Steffann et al., 2007).

In a previous study (Hattori et al., 2016), the metabolic signature analysis of iPSCs derived from a mitochondrial encoded LS mutation (m.10191T>C) showed differences in the abundance of pyruvate and lactate, among others. Interestingly, the metabolic difference between control and LS cells was reported to revert to normal after EB differentiation (Hattori et al., 2016). In our study, metabolomic analysis from neuralized EBs and organoids show that the observed changes in the metabolites are in line with the clinical observations of LS patients. Changes in blood and cerebral spinal fluid concentration of lactate and pyruvate are common diagnostic tools for LS (Hattori et al., 2016) and other mitochondrial diseases (Barshop, 2004; Buzkova et al., 2018; Esterhuizen et al., 2017; Rahman and Rahman, 2018). We also identified trends toward changes in other metabolites, like dihydroorotate and aspartate, that highlight the overall 
430 impact of LS mutations at different steps of the metabolic pathway (ETC complex III, TCA cycle,

431 and de novo nucleotide synthesis, and NADH/NAD+ ratio).

432 The metabolic dysregulation of the affected tissues in LS may have a direct effect on

433 mitochondrial morphology and function. Mitochondrial fragmentation is a hallmark of glycolytic

434 cell types such as stem cells and cancer cells (Chen and Chan, 2017; Rastogi et al., 2019).

435 Moreover, neurogenesis defects have been observed in the context of mitochondrial

436 morphology dysregulation and are considered to be upstream regulators of self-renewal and cell

437 fate decisions in stem cells (Khacho et al., 2016). In addition, energetic requirements have been

438 shown to directly impact the capacity of progenitor cells to migrate and thrive in 3D

439 environments (Zanotelli et al., 2018, 2019). Hence, mitochondrial morphology disruption

440 observed in the double mutant MT-ATP6/PDH organoids is expected when analyzed in

441 conjunction with the metabolic and developmental profile of these mutant organoids. To our

442 knowledge, this is the first time that mitochondrial morphology in the cortex has been analyzed

443 in a human model system of LS brain development and highlights the potential importance of

444 mitochondria network plasticity for the proper specification of cell fate and survival.

445 Here, we presented the characterization of three commercially available LS cell lines from

446 fibroblasts to cerebral organoids. We were able to identify new genetic alterations in these

447 samples by using whole-exome sequencing and mitochondrial DNA sequencing. We described

448 the effects of these mutations in a 3D cerebral organoid system. We aim to provide a 449 comprehensive phenotypic characterization of available patient samples to encourage their 450 utilization as model systems for uncovering the mechanisms underlying neuronal cell death in 451 the context of LS and for drug discovery. 


\section{Figure Legends}

Figure 1. Whole exome sequencing identifies novel mutations in Leigh syndrome fibroblasts. A.

457 Schematic of the WES and mitochondrial sequencing workflow. B. Representation of whole-

458 genome sequencing data, highlighting the top 20 genes containing high impact indels. C.

459 Representation of whole-genome sequencing data, highlighting the top 20 genes containing 460 high impact SNPs (increased likelihood of disrupting protein function). D. Mitochondrial 461 sequencing identifies novel mutations in LS fibroblasts. Representation of mitochondrial 462 sequencing data, highlighting mitochondrial genes containing mutations (transitions, deletions, or transversions). Red dots: represent DLD line. Green dots: represent the PDH line. Orange dots: represent the MT-ATP6/PDH line. PDH: Pyruvate dehydrogenase. DLD: Dihydrolipoyl dehydrogenase. MT-ATP6/PDH: Mitochondrially Encoded ATP Synthase Membrane Subunit 6/ Pyruvate dehydrogenase.

Figure 2. Induced pluripotent stem cells derived from Leigh syndrome patient fibroblasts are marker Pax6 (A) and qPCR for the ectodermal genes GATA3 and PAX6 (B). C-D.

471 Representative images of the endoderm marker SOX17 $(\mathrm{C})$ and qPCR for the ectodermal genes CDX2 and SOX17 (D). E-F. Representative images of the mesoderm markers Brachyury and CXCR4 (E) and qPCR for the mesodermal genes TBXT and NCAM (F). Scale bar: 100 $\mu m$.

Figure 3. Leigh syndrome derived NPCs are multipotent and do not show aberrant

476 mitochondrial morphology compared to control. A. C. Immunofluorescence for multipotency

477 markers. Neural progenitor cells stained by Pax6 and Nestin, neurons marked with ßIII-tubulin, 478 oligodendrocytes stained with Olig2, and astrocytes are marked with S100ß. Scale bar: 100 $\mu \mathrm{m}$

479 D. Representative super-resolution images of mitochondrial morphology (Mitotracker) in LS and 480 control NPCs. Scale bar: $5 \mu \mathrm{m}$. 
Figure 4. Generation of neuralized EBs from Leigh syndrome derived iPSCs lead to changes in EB diameter and the abundance of metabolites involved in central carbon metabolism. A. Schematic of EB generation protocol. B. Embryoid body diameter is increased in the three LS cell lines. C. Metabolite abundance pathway analysis. Top metabolic pathways affected in day 10 LS neuralized EBs. Statistical $p$ values from enrichment analysis are adjusted for multiple testing. Total: number of total compounds in the pathway. Hits: matched number from the uploaded data. Raw p: original p-value calculated from the enrichment analysis. Holm p: p-value adjusted by Holm-Bonferroni method. FDR p: adjusted p-value using False Discovery Rate. Impact: pathway impact value calculated from pathway topology analysis. ${ }^{*} p<0.05 ;{ }^{* *} p<$ $0.001,{ }^{* *} p<0.0001$

Figure 5. Three-dimensional differentiation reveals abnormalities during induction of neural rosettes in LS cell lines. A. Schematic of neural rosette generation protocol. B-D. Representative confocal images of neural rosettes $(C)$ show decreased numbers of neural rosettes per field in the DLD mutant line (D). Quantification of the lumen area $\left(\mu \mathrm{m}^{2}\right)$ indicates increased lumen area in the PDH and MT-ATP6/PDH mutant cell lines and a decreased lumen area in the DLD mutant line. Scale bar: $50 \mu \mathrm{m} .{ }^{*} p<0.05 ;{ }^{* *} p<0.001,{ }^{* * *} p<0.0001$.

Figure 6. Leigh syndrome derived brain organoids show a reduction in size and MT-ATP6/PDH mutant brain organoids show defects in SVZ/VZ and CP formation and aberrant mitochondrial

501 morphology in SOX2+ cells. A. Schematic of brain organoid generation protocol. B. Brain 502 organoid growth curves. LS derived brain organoids show reduction in size when grown for 100 503 days. C. Schematic representation of the expected organization of the brain organoids on day 504 30. D-E. Representative immunostaining confocal images of day 30 brain organoids. MT505 ATP6/PDH mutant presents severe disorganization of the SVZ/VZ markers PAX6 and TBR2, as 506 well as the neural progenitor marker NESTIN (D). MT-ATP6/PDH mutant does not express the 
507 CP and deep layer markers CTIP2 and TBR1 (E). Scale bar: 100 $\mu \mathrm{m}$. F. Representative confocal

508 images of day 30 brain organoids showing mitochondrial morphology (TOM20). The red line

509 divides the Sox2+ neural progenitor cells surrounding the lumen (L) from newly committed

510 neurons. MT-ATP6/PDH mutant organoids show disorganization and fragmentation of the

511 mitochondrial network compared to control. Scale bar: 10 $\mu \mathrm{m}$. SVZ: subventricular zone, VZ:

512 ventricular zone, CP: cortical plate, MZ: marginal zone. * $\mathrm{p}<0.05$ for Control and PDH mutant;

$513 \square p<0.05$ for Control and DLD mutant, $\phi p<$ for Control and MT-ATP6/PDH mutant.

515 Figure 7. Leigh syndrome derived brain organoids show defects in cortical layer formation at

516 day 100. A. Schematic representation of the expected organization of the brain organoids at day

517 100. B-D. Representative immunostaining confocal images of day 100 brain organoids. LS

518 derived brain organoids present reduced expression of the upper layer markers SATB2 (B),

519 BRN2 (C) and CUX1 (D) and deep layer marker CTIP2 (C \& D). Increased expression of the 520 astrocyte marker $\mathrm{S} 100 \beta$ was also noticed in the MT-ATP6/PDH mutant line. Scale bar: $100 \mu \mathrm{m}$.

521 SVZ: subventricular zone, VZ: ventricular zone, DL: deep layers UL: upper layers, MZ: marginal 522 zone.

523

524 
525 STAR Methods

526 Key Resource Table

\begin{tabular}{|c|c|c|}
\hline $\begin{array}{l}\text { REAGENT or } \\
\text { RESOURCE }\end{array}$ & SOURCE & IDENTIFIER \\
\hline \multirow{2}{*}{\multicolumn{3}{|c|}{$\begin{array}{l}\text { ANTIBODIES } \\
\text { Primary Antibodies (Immunocytochemistry) }\end{array}$}} \\
\hline & & \\
\hline Rabbit anti-PAX6 & $\begin{array}{l}\text { Cell Signaling } \\
\text { Technology }\end{array}$ & Cat \# 60433, AB_2797599 \\
\hline Rabbit anti-SOX17 & $\begin{array}{l}\text { Cell Signaling } \\
\text { Technology }\end{array}$ & Cat \# 81778S, AB_2650582 \\
\hline Rabbit anti-BRACHYURY & $\begin{array}{l}\text { Cell Signaling } \\
\text { Technologv }\end{array}$ & Cat \# 81694S, AB_2799983 \\
\hline $\begin{array}{l}\text { Mouse anti-CD184 } \\
\text { (CXCR4) }\end{array}$ & $\begin{array}{l}\text { STEMCELL } \\
\text { Technologies }\end{array}$ & Cat \# 60089 \\
\hline Mouse anti- $\beta 3$ tubulin & $\begin{array}{l}\text { Cell Signaling } \\
\text { Technology }\end{array}$ & Cat \# 4466, AB_10270973 \\
\hline Rabbit anti-S100 & Abcam & Cat \# ab868, AB 306716 \\
\hline Mouse anti-Olig2 & Millipore Sigma & Cat \# MABN50, AB_ 10807410 \\
\hline Rat anti- $\alpha$ tubulin & $\begin{array}{l}\text { Thermo Fisher } \\
\text { Scientific }\end{array}$ & Cat \# MA180017, AB_2210201 \\
\hline Mouse anti-ZO-1 & $\begin{array}{l}\text { Thermo Fisher } \\
\text { Scientific }\end{array}$ & Cat \# 339100, AB_2533147 \\
\hline Rabbit anti-CDK5RAP2 & Bethyl Laboratories & Cat \# IHC00063, AB_2076863 \\
\hline Mouse anti-Nestin & $\begin{array}{l}\text { STEMCELL } \\
\text { Technologies }\end{array}$ & Cat \# 60091, AB_2650581 \\
\hline Chicken anti-TBR2 & Millipore Sigma & Cat \# AB15894, AB 10615604 \\
\hline Mouse anti-Reelin & Millipore Sigma & Cat \# MAB5366, AB_2285132 \\
\hline Rat anti-CTIP2 & Abcam & Cat \# ab18465, AB_2064130 \\
\hline Rabbit anti-TBR1 & Abcam & Cat \# ab31940, AB 2200219 \\
\hline Rabbit anti-TOM20 & $\begin{array}{l}\text { Cell Signaling } \\
\text { Technology }\end{array}$ & Cat \# 42406, AB_2687663 \\
\hline Mouse anti-SATB2 & Abcam & Cat \# ab51502, AB_882455 \\
\hline $\begin{array}{l}\text { Mouse anti-BRN2 } \\
\text { (POU3F2) }\end{array}$ & Millipore Sigma & Cat \# MABD51, AB_11204531 \\
\hline Mouse anti-CASP (CUX1) & Abcam & Cat \# ab54583, AB_941209 \\
\hline \multicolumn{3}{|l|}{$\begin{array}{l}\text { Secondary Antibodies } \\
\text { (Immunocytochemistry) }\end{array}$} \\
\hline $\begin{array}{l}\text { Goat anti Chicken Alexa } \\
\text { Fluor } 647\end{array}$ & $\begin{array}{l}\text { Thermo Fisher } \\
\text { Scientific }\end{array}$ & Cat \# A-21449, AB_2535866 \\
\hline $\begin{array}{l}\text { Goat anti Rat Alexa Fluor } \\
647\end{array}$ & $\begin{array}{l}\text { Thermo Fisher } \\
\text { Scientific }\end{array}$ & Cat \# A-21247, AB_2535864 \\
\hline $\begin{array}{l}\text { Donkey anti Rabbit Alexa } \\
\text { Fluor } 647\end{array}$ & $\begin{array}{l}\text { Thermo Fisher } \\
\text { Scientific }\end{array}$ & Cat \# A-31573, AB_2536183 \\
\hline $\begin{array}{l}\text { Donkey anti Mouse Alexa } \\
\text { Fluor } 647\end{array}$ & $\begin{array}{l}\text { Thermo Fisher } \\
\text { Scientific }\end{array}$ & Cat \# A-31571, AB_162542 \\
\hline $\begin{array}{l}\text { Donkey anti Rabbit Alexa } \\
\text { Fluor } 546\end{array}$ & $\begin{array}{l}\text { Thermo Fisher } \\
\text { Scientific }\end{array}$ & Cat \# A-10040, AB_2534016 \\
\hline
\end{tabular}




\begin{tabular}{|c|c|c|}
\hline $\begin{array}{l}\text { Donkey anti Mouse Alexa } \\
\text { Fluor } 546\end{array}$ & $\begin{array}{l}\text { Thermo Fisher } \\
\text { Scientific }\end{array}$ & Cat \# A-10036, AB_2534012 \\
\hline $\begin{array}{l}\text { Donkey anti Rabbit Alexa } \\
\text { Fluor } 488\end{array}$ & $\begin{array}{l}\text { Thermo Fisher } \\
\text { Scientific }\end{array}$ & Cat \# A-21206, AB_2535792 \\
\hline $\begin{array}{l}\text { Donkey anti Mouse Alexa } \\
\text { Fluor } 488\end{array}$ & $\begin{array}{l}\text { Thermo Fisher } \\
\text { Scientific }\end{array}$ & Cat \# A-21202, AB_141607 \\
\hline \multicolumn{3}{|c|}{ Primary Antibodies (Western Blotting) } \\
\hline Rabbit anti-PAX6 & $\begin{array}{l}\text { Cell Signaling } \\
\text { Technology }\end{array}$ & Cat \# 60433, AB_2797599 \\
\hline Mouse anti-Nestin & $\begin{array}{l}\text { STEMCELL } \\
\text { Technologies }\end{array}$ & Cat \# 60091, AB_2650581 \\
\hline Rabbit anti-Sox2 & $\begin{array}{l}\text { Cell Signaling } \\
\text { Technology }\end{array}$ & Cat \# 3579, AB_2195767 \\
\hline Mouse anti- a tubulin & Sigma-Aldrich & Cat \# T9026, AB_477593 \\
\hline \multicolumn{3}{|c|}{ Secondary Antibodies -HRP conjugated (Western Blotting) } \\
\hline $\begin{array}{l}\text { Peroxidase AffiniPure } \\
\text { Donkey Anti-Rabbit lgG } \\
(\mathrm{H}+\mathrm{L})\end{array}$ & $\begin{array}{l}\text { Jackson } \\
\text { ImmunoResearch } \\
\text { Inc }\end{array}$ & Cat \# 711-035-152, AB_10015282 \\
\hline $\begin{array}{l}\text { Peroxidase AffiniPure } \\
\text { Donkey Anti-Mouse IgG } \\
(\mathrm{H}+\mathrm{L})\end{array}$ & $\begin{array}{l}\text { Jackson } \\
\text { ImmunoResearch } \\
\text { Inc }\end{array}$ & Cat \# 715-035-151, AB_2340771 \\
\hline \multicolumn{3}{|c|}{ CHEMICALS, PEPTIDE, AND RECOMBINANT PROTEINS } \\
\hline $\begin{array}{l}\text { Y-27632 Rho/Rock } \\
\text { pathway inhibitor }\end{array}$ & $\begin{array}{l}\text { STEMCELL } \\
\text { Technologies }\end{array}$ & Cat \# 72307 \\
\hline Dorsomorphin & Millipore Sigma & Cat \# P5499 \\
\hline SB431542 & REPROCELL & Cat \# 04-0010-10 \\
\hline Etoposide & Millipore Sigma & Cat \# E1383 \\
\hline $\begin{array}{l}\text { Carbonyl cyanide 3- } \\
\text { chlorophenylhydrazone } \\
\text { (CCCP) }\end{array}$ & Sigma Aldrich & Cat \# C2759 \\
\hline Nocodazole & Sigma Aldrich & Cat \# M1404 \\
\hline Neocarzinostatin & Sigma Aldrich & Cat \# 9162 \\
\hline \multicolumn{3}{|c|}{ CRITICAL COMMERCIAL ASSAYS AND KITS } \\
\hline PluriTest Assay & $\begin{array}{l}\text { Thermo Fisher } \\
\text { Scientific }\end{array}$ & Cat\# A38154 \\
\hline KaryoStat Assay & $\begin{array}{l}\text { Thermo Fisher } \\
\text { Scientific }\end{array}$ & Cat\# A38153 \\
\hline $\begin{array}{l}\text { Mitochondrial DNA } \\
\text { sequencing }\end{array}$ & Girihlet & \\
\hline Whole Exome sequencing & Genewiz LLC & \\
\hline $\begin{array}{l}\text { CytoTune iPS } 2.0 \text { Sendai } \\
\text { Reprogramming Kit }\end{array}$ & $\begin{array}{l}\text { Thermo Fisher } \\
\text { Scientific }\end{array}$ & Cat \# A16517 \\
\hline $\begin{array}{l}\text { STEMdiff Trilineage } \\
\text { Differentiation Kit }\end{array}$ & $\begin{array}{l}\text { STEMCELL } \\
\text { Technologies }\end{array}$ & Cat\# 05230 \\
\hline NeuroCult ${ }^{\mathrm{TM}}$ media & STEMCELL & Cat \# 05752 \\
\hline
\end{tabular}




\begin{tabular}{|c|c|c|}
\hline & Technologies & \\
\hline Astrocyte medium & ScienCell & Cat \# 1801 \\
\hline $\begin{array}{l}\text { CellTiter Blue Viability } \\
\text { Assay }\end{array}$ & Promega & Cat \# G8081 \\
\hline \multicolumn{3}{|l|}{ DEPOSITED DATA } \\
\hline $\begin{array}{l}\text { Raw and analyzed } \\
\text { sequencing data }\end{array}$ & $\begin{array}{l}\text { Done by Creative } \\
\text { Solutions (J.P.C, } \\
\text { Vanderbilt University }\end{array}$ & $\begin{array}{l}\text { https://www.ncbi.nlm.nih.gov/sra/PRJNA626388 } \\
\text { https://vandydata.github.io/Romero-Morales- } \\
\text { Gama-Leigh-Syndrome-WES/ }\end{array}$ \\
\hline \multicolumn{3}{|c|}{ EXPERIMENTAL MODELS: CELL LINES } \\
\hline $\begin{array}{l}\text { AG16409 control } \\
\text { fibroblasts }\end{array}$ & Coriell Institute & $\begin{array}{l}\text { https://www.coriell.org/0/Sections/Search/Sample } \\
\text { Detail.aspx?Ref=AG16409\&Product=CC }\end{array}$ \\
\hline $\begin{array}{l}\text { GM13411 (MT- } \\
\text { ATP6/PDH) fibroblasts }\end{array}$ & Coriell Institute & $\begin{array}{l}\text { https://www.coriell.org/0/Sections/Search/Sample } \\
\text { Detail.aspx?Ref=GM13411\&Product=CC }\end{array}$ \\
\hline $\begin{array}{l}\text { GM03672 (PDH Mutant) } \\
\text { fibroblasts }\end{array}$ & Coriell Institute & $\begin{array}{l}\text { https://www.coriell.org/0/Sections/Search/Sample } \\
\text { Detail.aspx?Ref=GM03672\&Product=CC }\end{array}$ \\
\hline $\begin{array}{l}\text { GM01503 (DLD Mutant) } \\
\text { fibroblasts }\end{array}$ & Coriell Institute & $\begin{array}{l}\text { https://www.coriell.org/0/Sections/Search/Sample } \\
\text { Detail.aspx?Ref=GM01503\&Product=CC }\end{array}$ \\
\hline \multicolumn{3}{|c|}{ SEQUENCE-BASED REAGENTS } \\
\hline \multicolumn{3}{|c|}{ Primers for Trilineage assay } \\
\hline OCT4 & $\begin{array}{l}\text { Integrated DNA } \\
\text { Technologies }\end{array}$ & $\begin{array}{ll}\text { Forward } & \text { GGGCTCTCCCATGCATTCAAAC } \\
\text { Reverse } & \text { CACCTTCCCTCCAACCAGTTGC } \\
\end{array}$ \\
\hline NANOG & $\begin{array}{l}\text { Integrated DNA } \\
\text { Technologies }\end{array}$ & $\begin{array}{l}\text { Forward } \\
\text { TGGGATTTACAGGCGTGAGCCAC } \\
\text { Reverse } \\
\text { AAGCAAAGCCTCCCAATCCCAAAC }\end{array}$ \\
\hline GAPDH & $\begin{array}{l}\text { Integrated DNA } \\
\text { Technologies }\end{array}$ & $\begin{array}{ll}\text { Harvard PrimerBank, ID: 378404907c2 } \\
\text { Forward } & \text { ACAACTTTGGTATCGTGGAAGG } \\
\text { Reverse } & \text { GCCATCACGCCACAGTTTC }\end{array}$ \\
\hline GATA3 & $\begin{array}{l}\text { Integrated DNA } \\
\text { Technologies }\end{array}$ & $\begin{array}{l}\text { Forward TGGAGGAGGAATGCCAATGGG } \\
\text { Reverse } \\
\text { GCCGGGTTAAACGAGCTGTTCTTG }\end{array}$ \\
\hline$P A X 6$ & $\begin{array}{l}\text { Integrated DNA } \\
\text { Technologies }\end{array}$ & \begin{tabular}{ll}
\multicolumn{3}{l}{ Harvard Primer Bank, ID: 189083679c1 } \\
Forward & TGGGCAGGTATTACGAGACTG \\
Reverse & ACTCCCGCTTATACTGGGCTA
\end{tabular} \\
\hline$C D \times 2$ & $\begin{array}{l}\text { Integrated DNA } \\
\text { Technologies }\end{array}$ & $\begin{array}{l}\text { Forward } \\
\text { CTGGAGCTGGAGAAGGAGTTTCAC } \\
\text { Reverse } \\
\text { GACACTTCTCAGAGGACCTGGCTG }\end{array}$ \\
\hline SOX17 & $\begin{array}{l}\text { Integrated DNA } \\
\text { Technologies }\end{array}$ & $\begin{array}{ll}\text { Harvard Primer Bank, ID:145275218c1 } \\
\text { Forward } \\
\text { Reverse }\end{array}$ \\
\hline$T B X T$ & $\begin{array}{l}\text { Integrated DNA } \\
\text { Technologies }\end{array}$ & $\begin{array}{l}\text { Forward } \\
\qquad \text { ACAATGCCAGCCCACCTACCAG }\end{array}$ \\
\hline
\end{tabular}




\begin{tabular}{|c|c|c|}
\hline & & $\begin{array}{l}\text { Reverse } \\
\text { CGTACTGGCTGTCCACGATGTCTG }\end{array}$ \\
\hline NCAM & $\begin{array}{l}\text { Integrated DNA } \\
\text { Technologies }\end{array}$ & $\begin{array}{ll}\text { Harvard Primer Bank, ID:316659209c1 } \\
\text { Forward } & \text { GGGGTTCTTGTCAGTAGC } \\
\text { Reverse } & \text { TTCAGGTTCACCAATCGCTGT }\end{array}$ \\
\hline \multicolumn{3}{|c|}{ SOFTWARE AND ALGORITHMS } \\
\hline Image Studio ${ }^{\mathrm{TM}}$ Lite & LI-COR & $\begin{array}{l}\text { https://www.licor.com/bio/image-studio- } \\
\text { lite/download }\end{array}$ \\
\hline Fiji & $\begin{array}{l}\text { Schindelin et al., } \\
2012\end{array}$ & https://imagej.net/Fiji \\
\hline GraphPad Prism v8.1.2 & GraphPad & $\begin{array}{l}\text { https://www.graphpad.com/scientific- } \\
\text { software/prism/ }\end{array}$ \\
\hline NIS-Elements & Nikon Instruments & $\begin{array}{l}\text { https://www.microscope.healthcare.nikon.com/pr } \\
\text { oducts/software/nis-elements }\end{array}$ \\
\hline MetaboAnalyst 4.0 & $\begin{array}{l}\text { (Chong and Xia, } \\
\text { 2018; Chong et al., } \\
\text { 2018, 2019; Xia and } \\
\text { Wishart, 2010, } \\
\text { 2011a, 2011b; Xia et } \\
\text { al., 2009) }\end{array}$ & https://www.metaboanalyst.ca/home.xhtml \\
\hline SnpSift & $\begin{array}{l}\text { (Cingolani et al., } \\
\text { 2012) }\end{array}$ & http://snpeff.sourceforge.net/SnpSift.html \\
\hline R 3.5.3 & R Foundation & https://www.r-project.org/ \\
\hline BioCircos & (Cui et al., 2016) & $\begin{array}{l}\text { https://cran.r- } \\
\text { project.org/web/packages/BioCircos/index.html }\end{array}$ \\
\hline \multicolumn{3}{|r|}{ 等 } \\
\hline Mitotracker Red CMXRos & Fisher Scientific & Cat \# M7512 \\
\hline Matrigel $^{\mathrm{TM}}$ & Corning & Cat \# 354277 \\
\hline $\begin{array}{l}\text { Gentle dissociation } \\
\text { solution }\end{array}$ & $\begin{array}{l}\text { STEMCELL } \\
\text { Technologies }\end{array}$ & Cat \# 07174 \\
\hline $\begin{array}{l}\text { Aggrewell }{ }^{\mathrm{TM}} 80024 \text {-well } \\
\text { plate }\end{array}$ & $\begin{array}{l}\text { STEMCELL } \\
\text { Technologies }\end{array}$ & Cat \# 34815 \\
\hline $\begin{array}{l}\text { AggreWell TM Rinsing } \\
\text { Solution }\end{array}$ & $\begin{array}{l}\text { STEMCELL } \\
\text { Technologies }\end{array}$ & Cat \# 07010 \\
\hline $\begin{array}{l}\text { STEMdiff'T Cerebral } \\
\text { Organoid Kit }\end{array}$ & $\begin{array}{l}\text { STEMCELL } \\
\text { Technologies }\end{array}$ & Cat \# 08570 \\
\hline $\begin{array}{l}\text { STEMdiff TM Cerebral } \\
\text { Organoid Maturation Kit }\end{array}$ & $\begin{array}{l}\text { STEMCELL } \\
\text { Technologies }\end{array}$ & Cat \# 08571 \\
\hline
\end{tabular}

528 Lead Contact and Materials Availability

529 Further information and requests for resources and reagents should be directed to the Lead

530 Contact, Vivian Gama (vivian.gama@vanderbilt.edu). 
533 The Coriell cell line IDs were as follows: GM01503, GM03672, GM1341. Information about the

534 Leigh syndrome cell lines used in this study can be found in Supplementary Table1. Control skin

535 fibroblast cell line AG16409 was also obtained from Coriell Institute, Philadelphia, PA. The

536 donor was a 12-year-old apparently healthy Caucasian male.

537 Fibroblasts were maintained in Dulbecco's Modified Eagle Medium: Nutrient Mixture F-12

538 DMEM/F-12 (Gibco cat \# 11330032) supplemented with 10\% Fetal bovine serum (Sigma cat\#

$539 \mathrm{~F} 2442$ ) in $100 \mathrm{~mm}$ cell culture plates (Eppendorf, cat \# 0030702115) in a $37^{\circ} \mathrm{C} 5 \% \mathrm{CO} 2$

540 incubator.

$542 \quad$ Method Details

\section{Whole Exome sequencing}

544 Fibroblast cell pellets from each cell line (>1 million cells) were shipped on dry ice for whole545 genome exome sequencing to Genewiz, Plainfield, NJ. The Illumina HiSeq-X was used to 546 perform 150nt paired-end sequencing.

\section{Mitochondrial sequencing}

549 Fibroblast cell pellets from each patient ( $>1$ million cells) were shipped on dry ice for 550 mitochondrial sequencing to Girihlet Inc. Oakland, CA. The sequencing configuration used was 551 80bp single-end sequencing, 20 million reads per sample.

\section{hiPSC Generation and Characterization}

554 Human fibroblasts were purchased from healthy control and patients (Coriell Institute,

555 Philadelphia, PA, USA). Induced pluripotent stem cells were derived from human fibroblasts 556 using Sendai virus-based reprogramming kit (CytoTune-iPS Sendai Reprogramming Kit; cat \#.

557 A13780-01; Thermo Fisher), according to manufacturer's instructions. After 3-4 weeks, 2-3

558 colonies per sample were transferred to fresh 6-well plates and were expanded and gardened 
559 for 3 passages before freezing. All iPSC cell lines were maintained in E8 medium in plates

560 coated with Matrigel (Corning, cat \# 354277) at $37^{\circ} \mathrm{C}$ with $5 \% \mathrm{CO}_{2}$. Culture medium was

561 changed daily. Cells were checked daily for differentiation and were passaged every 3-4 days

562 using Gentle dissociation solution (STEMCELL Technologies, cat \# 07174). All experiments

563 were performed under the supervision of the Vanderbilt Institutional Human Pluripotent Cell

564 Research Oversight (VIHPCRO) Committee.

565

566 Analysis of Pluripotency

567 Pluripotency of each iPSC clone was determined using a microarray-based tool known as

568 PluriTest (Thermo Fisher; cat\# A38154) as an alternative to the teratoma assay. Samples were

569 outsourced to Thermo Fisher for PluriTest and further analysis. Low passage iPSC cell pellets

570 (>1 million cells) were frozen and shipped on dry ice. Additionally, the expression of

571 pluripotency genes POU5F1 and NANOG was assessed by qPCR.

572

573 Analysis of Chromosomal abnormalities

574 The presence of any chromosomal abnormalities in the newly generated iPSCs was determined

575 using a microarray-based tool known as KaryoStat (Thermo Fisher; cat\# A38153) as an

576 alternative to chromosomal G-banding. Samples were outsourced to Thermo Fisher for

577 KaryoStat and further analysis. Low passage iPSC cell pellets ( $>1$ million cells) were frozen and

578 shipped on dry ice to Thermo Fisher.

579

580 Trilineage differentiation

581 The STEMdiff Trilineage differentiation kit (STEMCELL Technologies, cat\# 05230) was used to

582 functionally validate the ability of newly established iPSCs to differentiate into three germ layers,

583 as per the manufacturer's instructions. Single-cell suspensions of $2 \times 10^{6}$ cells/well, $5 \times 10^{5}$

584 cells/well, $2 \times 10^{6}$ cells/well were seeded for ectoderm, mesoderm, and endoderm, respectively, 
585 in their corresponding medium at day 0 in 6 well plates. The cultures were maintained for 7

586 days, 5 days, and 5 days for ectoderm, mesoderm, and endoderm, respectively. The

587 differentiation was assessed by immunocytochemistry and qPCR.

588

\section{NPC differentiation and multipotency characterization}

590 For monolayer differentiation of the iPSCs into NPCs, cells were dissociated into single cells 591 using Gentle Cell Dissociation Reagent (STEMCELL Technologies, cat \# 07174) for 8 minutes 592 at $37^{\circ} \mathrm{C}$. Live cell counts were performed using Trypan blue $(0.4 \%)$ staining (Invitrogen, cat \# 593 T10282) using a Countess ${ }^{\mathrm{TM}}$ Automated Cell Counter. Cells were then seeded in a Matrigelcoated 6-well plate (Eppendorf, cat \# 0030720113) to a $2.5 \times 10^{6}$ cells/well with dual SMAD 595 inhibitor media supplemented with Dorsomorphin $(1 \mu \mathrm{M})$ and SB431542 (10 $\mu \mathrm{M})$ (Chambers et al., 2009) supplemented with ROCK inhibitor. Daily media changes were performed and passaging of the cells was done every 7-9 days. Cells for NPC marker analysis were collected at the end of the first 9 days of differentiation. $405 \mathrm{~nm}$ and $561 \mathrm{~nm}$ lasers. Images presented herein are maximum intensity projections after

604 image stacks were first acquired (5 phase shifts and 3 rotations of diffraction grating, 605 120nm/axial step via piezo) and subsequent stack reconstruction in NIS-Elements software 606 (Nikon Instruments, Inc.). Other than linear intensity scaling, no further image processing was 607 performed post-reconstruction.

608 For multipotency analysis, culture media was changed to NeuroCult ${ }^{\mathrm{TM}}$ media and maintained for 
610

611

612

613

614

615 616 (Excelitas).

617

618

619

620

621

622

623

624

625

626

627

628

629

630

631

632

633

634

635

Astrocyte differentiation was performed by seeding on a Matrigel-coated plate $1.5 \times 10^{6} \mathrm{cells} / \mathrm{cm}^{2}$ (TCW et al., 2017). The following day, the media was changed to Astrocyte medium (ScienCell, cat \# 1801) and maintained for 20 days. Full media changes were done every 2 days. Samples were then fixed and stained for an astrocyte marker. Images were acquired with a Nikon Instruments Ti2 inverted fluorescence widefield microscope equipped with a Plan Apo Lambda 20X 0.75 NA objective, DS-Qi2 camera (Nikon Instruments), and X-Cite 120LED light source

\section{Neural rosette differentiation}

To generate neural rosettes, we dissociated the cells into a single-cell suspension and seeded $3.0 \times 10^{6}$ cells/well of an Aggrewell ${ }^{\mathrm{TM}} 800$ in dual SMAD inhibitor media. EBs were incubated at $37^{\circ} \mathrm{C}$ with $5 \% \mathrm{CO}$, with minimal disruption during the first 48 hours. Media changes, $50-75 \%$ of the total volume, were performed every 2 days. On Day 5, EBs were harvested according to the manufacturer protocol and transferred to a 35mm imaging plate (Cellvis, cat \# D35-14-1.5-N) coated with Matrigel. Daily media changes were performed up to day 9 when cells were fixed with 100\% ice-cold Methanol (Fisher Scientific, cat \# A454-4). Images were acquired on a Nikon Instruments Ti2 inverted fluorescence microscope, equipped with a Yokogawa X1 spinning disk head, Andor DU-897 EMCCD, Plan Apo Lambda 0.75 NA 20X objective for representative figures, and Plan Fluor 0.45 NA 10X objective for neural rosette quantification, piezo Z-stage, as well as 405-,488-,561-, and 647 -nm lasers. Acquisition and analysis were performed using NISElements. Neural rosette quantification was accomplished by scripting a segmentation-based image analysis routine to detect, enumerate, and measure rosette lumen area based on the ZO1 signal. Briefly, max intensity projections of each field were generated, followed by GPU-based denoising of the resulting image. Intensity-based thresholding was then applied based on criteria established for ZO-1 signal segmentation using control images. Restrictions on resultant binaries were implemented to throw out binaries intersecting image borders, morphometries 
636

637

638

639 for further analysis.

640

654 ImageJ.

657 Tissue preparation was performed as described in (Romero-Morales et al., 2019). Briefly, 658 organoids were fixed in 4\% Paraformaldehyde in Phosphate Buffered Saline (PBS), washed 3 659 times with PBS, and then incubated in $30 \%$ sucrose solution overnight at $4{ }^{\circ} \mathrm{C}$. Organoids were 660 embedded in 7.5\% gelatin/10\% sucrose solution (Sigma, catalog G1890-100G and S7903- 
662 slides were washed with PBS before permeabilization with $0.2 \%$ Triton-X in PBS for $1 \mathrm{hr}$.

663 Tissues were blocked with blocking medium consisting of $10 \%$ donkey serum in PBS with $0.1 \%$

664 Tween-20 (PBST) for 30 min. Incubation with primary and secondary antibodies was done using

665 standard methods. Confocal images of the organoids were acquired using the aforementioned

666 spinning disk microscope with Plan Fluor 10X 0.45 NA and Plan Apo Lambda 0.75 NA 20X

667 objectives (macrostructures) and Apo TIRF 1.49 NA 100X objective (mitochondria imaging).

668 NIS-Elements software was used for image acquisition and rendering.

669

670

\section{RNA Extraction and Synthesis of cDNA}

671 Cells cultured in 6 well plate, were collected after a wash with PBS, using $600 \mu$ l Trizol reagent.

672 The samples were spun down at $12,000 \mathrm{~g}$ after the addition of $130 \mu$ of chloroform and

673 incubated at room temperature for 3 minutes. The aqueous phase of the sample was collected

$674200 \mu$ lat a time until reaching the edge of phase separation. RNA precipitation was done by

675 incubating with $300 \mu \mathrm{l}$ of isopropanol for 25 minutes, followed by centrifugation at $12,000 \mathrm{~g}$ for 10

$676 \min$ at $4^{\circ} \mathrm{C}$. The RNA pellet was washed with ethanol, semi-dried, and resuspended in $30 \mu \mathrm{l}$ of

677 DEPC water. After quantification and adjusting the volume of all the samples to $1 \mu \mathrm{g} / \mu \mathrm{l}$, the 678 samples were treated with DNAse (New England Biolabs, cat \# M0303). 10 $\mu$ l of this volume was 679 used to generate cDNA using the manufacturer's protocol (Thermofisher, cat\#4368814)

\section{Quantitative RT PCR}

682 lug of cDNA sample was used to run a q-PCR for the primers mentioned in the table. 683 QuantStudio 3 Real-Time PCR machine, SYBR green master mix (Thermo Fisher, 684 cat\#4364346), and manufacturer instructions were used to set up the assay. 
Cells were fixed with 4\% paraformaldehyde (Electron Microscopy Sciences, cat \# 15710-S) in PBS for 20 min at $4^{\circ} \mathrm{C}$. Blocking and permeabilization were done in $5 \%$ donkey serum (Jackson ImmunoResearch Inc, cat \# 017-000-121) + 0.3\% Triton X-100 (Sigma Aldrich, cat \# T9284) in TBS for $1 \mathrm{hr}$ at room temperature. After this, cells were treated with primary and secondary antibodies using standard methods. Cells were mounted in Vectashield (Vector Laboratories, cat \# H-1000) prior to imaging.

\section{Western Blotting}

695 Cultured cells were lysed in 1\% Triton buffer containing PMSF (ThermoFisher Scientific, cat \# 36978), PhosSTOP (Roche, cat \# 4906837001), and protease inhibitor cocktail (Roche, cat \# 4693132001). Protein concentrations were determined using the bicinchoninic acid (BCA) method (Thermo Scientific, cat \# 23227). Gel samples were prepared by mixing $30 \mu \mathrm{g}$ of protein with LDS sample buffer (Life Technologies, cat \# NP0007) and 2-Mercaptoethanol (BioRad, cat \# 1610710) and boiled at $95^{\circ} \mathrm{C}$ for 5 minutes. Samples were run on 4-20\% Mini-PROTEAN TGX precast gels (BioRad, cat \# 4561096) and transferred onto polyvinylidene difluoride (PVDF) membrane (BioRad, cat \# 1620177) overnight at $4^{\circ} \mathrm{C}$. Membranes were blocked in 5\% milk in TBST prior to primary antibody incubation. Antibodies used for Western blotting are described in the Key Resource table.

705

\section{Cell titer blue assay}

707 After the 24-h exposure to individual treatments of $50 \mu \mathrm{M}$ etoposide, $80 \mu \mathrm{M} \mathrm{CCCP,} 100 \mathrm{ng} / \mathrm{mL}$ 708 nocodazole, and $5 \mathrm{ng} / \mathrm{mL}$ neocarzinostatin, $20 \mu \mathrm{l}$ of Cell Titer Blue reagent from Cell Titer Blue 709 assay (Promega, cat \# G8081) was added to each well of 96 well plate. Background 710 fluorescence was calculated by adding $10 \%$ Triton in PBS to some wells. The fluorescence 711 generated by the reduction of resazurin to resorufin by live cells was measured using a 
$713 \mathrm{~nm})$.

\section{Metabolomics analysis}

716 Neuralized embryoid bodies were generated by seeding $3 \times 10^{6}$ cells/well in an Aggewell $800^{\mathrm{TM}}$.

717 Media change was performed on days 2 and 4. On day 5, EBs were transferred to a low 718 attachment $60 \mathrm{~mm}$ plate and maintained in suspension with daily media changes. On day 10, $719 \sim 150$ EBs were collected in a $1.5 \mathrm{~mL}$ centrifuge tube, rinsed with ice-cold sterile $0.9 \% \mathrm{NaCl}$ and 720 flash-frozen in liquid nitrogen. For organoids, at least 4 individual organoids were collected at 721 day 40 , rinsed with ice-cold sterile $0.9 \% \mathrm{NaCl}$ and flash-freeze in liquid nitrogen.

722 For metabolite extraction, cells were resuspended in $225 \mathrm{uL}$ of cold $80 \%$ HPLC grade 723 methanol/20\% HPLC grade water per $1 \times 10^{6}$ cells. After resuspension, cells were flash-frozen in 724 liquid nitrogen and thawed rapidly in a $37^{\circ} \mathrm{C}$ water bath 3 times. Next debris was removed by centrifugation at max speed in a tabletop microcentrifuge at $4^{\circ} \mathrm{C}$ for $15 \mathrm{~min}$. Metabolitecontaining supernatant was transferred to a new tube, dried, and resuspended in $50 \%$ acetonitrile while the pellet was used for protein quantification. Samples were analyzed by UltraHigh-Performance Liquid Chromatography and High-Resolution Mass Spectrometry and Tandem Mass Spectrometry (UHPLC-MS/MS). Specifically, the system consisted of a Thermo Q-Exactive in line with an electrospray source and an Ultimate3000 (Thermo) series HPLC consisting of a binary pump, degasser, and auto-sampler outfitted with an Xbridge Amide

732 column (Waters; dimensions of $4.6 \mathrm{~mm} \times 100 \mathrm{~mm}$ and a $3.5 \mu \mathrm{m}$ particle size). Mobile phase A 733 contained 95\% (vol $/ \mathrm{vol})$ water, 5\% (vol/vol) acetonitrile, 10mM ammonium hydroxide, 10mM 734 ammonium acetate, $\mathrm{pH}=9.0$; and mobile phase $\mathrm{B}$ was $100 \%$ Acetonitrile. The gradient was as 735 follows: $0 \mathrm{~min}, 15 \% \mathrm{~A} ; 2.5 \mathrm{~min}, 30 \% \mathrm{~A} ; 7 \mathrm{~min}, 43 \% \mathrm{~A} ; 16 \mathrm{~min}, 62 \% \mathrm{~A} ; 16.1-18 \mathrm{~min}, 75 \% \mathrm{~A} ; 18-$ $73625 \mathrm{~min}, 15 \% \mathrm{~A}$ with a flow rate of $400 \mu \mathrm{L} / \mathrm{min}$. The capillary of the ESI source was set to $275^{\circ} \mathrm{C}$, 737 with sheath gas at 45 arbitrary units, auxiliary gas at 5 arbitrary units, and the spray voltage at 
4.0kV. In positive/negative polarity switching mode, an $\mathrm{m} / \mathrm{z}$ scan range from 70 to 850 was chosen, and MS1 data was collected at a resolution of 70,000 . The automatic gain control (AGC) target was set at $1 \times 10^{6}$ and the maximum injection time was $200 \mathrm{~ms}$. The top 5 precursor ions were subsequently fragmented, in a data-dependent manner, using the higher energy collisional dissociation (HCD) cell set to $30 \%$ normalized collision energy in MS2 at a resolution power of 17,500. Data acquisition and analysis were carried out by Xcalibur 4.1 software and Tracefinder 4.1 software, respectively (both from Thermo Fisher Scientific). The peak area for each detected metabolite was normalized by the total ion current which was determined by integration of all of the recorded peaks within the acquisition window.

\section{Bioinformatic Analysis}

Bioinformatic analysis began with Variant Call Format (VCF) files provided by GENEWIZ (see Whole Exome sequencing section above), both for SNP and indels. SnpSift version 4.3t (PMID: 22435069) was used to process and filter these files for downstream analysis. Details extracted included gene symbol, Entrez gene ID and name, UniProt ID, Ensembl ID, chromosome and position, reference variant, alternative variant, quality of the call, allele name, type of SNP, impact of the SNP, and the genotype of each sample. From these filtered outputs, we generated SNP/indel reports that allowed us to look at sample-specific SNPs and indels, as well as perform aggregate-level functions for grouping and statistical analysis.

To generate the SNP/indel circular chromosome plots, the top 20 genes that had variants in all three samples were plotted, ranked by frequency of variants per gene. The outside track is used to visualize the chromosomes and marked gene locations. For each sample, we used a single track to show the variant frequency as a circular scatter plot, with the height of the scatter points representative of the variant quality metric, which is a Phred-scaled probability that a REF/ALT polymorphism exists at the variant site. Similarly, for SNPs in the mitochondrial chromosome, we used the same approach for visualization. 


\section{Quantification and Statistical Analysis}

766

767

768

No statistical methods were used to pre-determine sample sizes. All experiments were performed with a minimum of 3 biological replicates unless specified. Statistical significance was determined by unpaired Student's t-test or by one- or two-way ANOVA as appropriate for each experiment. GraphPad Prism v8.1.2 was used for all statistical analysis and data visualization. Error bars in all bar graphs represent standard error of the mean or standard deviation as described for each Figure, while scattered dot plots were represented with boxes (with median and SD) and whiskers (minimum and maximum values).

For neural rosette experiments, ROI were randomly selected using the nuclear (DAPI) staining channel. Images were processed with NIS Elements software with our Neural rosette lumen identification Macro. Outliers were removed from the neural rosette area analysis as postprocessing quality control for the NIS Element macro using GraphPad Prism v8.1.2. ROUT (Robust regression and Outlier removal) method was used with a False Discovery Rate of $1 \%$.

For cerebral organoid experiments, 4 independent batches were generated. At time points day 30 and day100, at least 5 organoids per cell line were collected. Immunofluorescence images of at least 3 independent organoids were acquired per condition slide. Image processing was done by NIS Elements and Fiji software. Organoid efficiency evaluation was performed on day 10 using $4 \mathrm{X}$ transmitted-light images acquired using an EVOS® $\mathrm{XL}$ microscope. Two observers were blinded to the cell line identifier and counted the number of normal and defective (no epithelial buds or more than $75 \%$ of the area is not developed) organoids. Criteria for normal and defective organoids was based on (Lancaster and Knoblich, 2014).

For the metabolomics experiments, two independent LC/MS runs of $\sim 150-200$ neuralized EBs/cell line/replica were utilized with enough material to account for $3 \times 10^{6}$ cells/run. For the cerebral organoid metabolomics, one replica of day 40 organoids was performed, with 4 samples per genotype. 


\section{Software and Data Availability}

792 All raw data in FastQ format for whole-exome sequencing and mitochondrial sequencing have 793 been deposited to the Short Read Archive as BioProject PRJNA626388, available at 794 https://www.ncbi.nlm.nih.gov/sra/PRJNA626388. All source code and documents are available 795 via https://vandydata.github.io/Romero-Morales-Gama-Leigh-Syndrome-WES/.

\section{Author contributions}

798 A.R.M. and V.G. designed experiments, interpret the data, and wrote the manuscript. A.R.M., A.R., G.L.R., and M.L.R. performed experiments and analyzed data with technical support of H.T. J.P.C. and L.H. analyzed the genomic data, generated the corresponding figures, and the associated method section. P.M.A provided the pluripotency data analysis and technical support for data analysis. B.M generated the neural rosette analysis macro for NIS Elements. N.S.C. and G.S.M provided technical support, led the experimental design and data analysis for metabolomics and its corresponding method section.

805

\section{Conflict of interests}

807 The authors declare no competing interests.

\section{Acknowledgments}

810 We thank Dr. Nicholas Mignemi (Vanderbilt Nikon Center for Excellence) for his technical

811 support with image acquisition and processing. We would like to thank members of the Gama

812 Laboratory for helpful discussions and comments on the manuscript. Funding was provided by 813 the following grants: 1R35GM128915-01 (to VG); 1R21 CA227483-01A1 (to VG); the Precision

814 Medicine and Mental Health Initiative sponsored by the Vanderbilt Brain Institute (to VG). Image 815 acquisition and analysis were performed in part through the use of the Nikon Center of 
816 Excellence within the Vanderbilt Cell Imaging Shared Resource (supported by NIH grants

817 CA68485, DK20593, DK58404, DK59637, and EY08126), Vanderbilt University Medical

818 Center's Translational Pathology Shared Resource supported by NCI/NIH Cancer Center

819 Support Grant 2P30 CA068485-14, and the Vanderbilt Mouse Metabolic Phenotyping Center

820 Grant 5U24DK059637-13. Whole exome sequencing and mitochondrial sequencing results

821 were analyzed by Creative Solutions. Metabolite measurements were performed by the

822 Northwestern University RHLCCC Metabolomics Core (Peng Gao) and were supported by the

823 following $\mathrm{NIH}$ grants to N.S.C.: NIH2PO1HL071643-11A1, NIH1R35CA197532-01,

824 NIH1PO1AG049665-01 and NIH/NCI grant to G.S.M: T32CA09560. 


\section{References}

827

828

829

830

831

832

833

834

835

836

837

838

839

840

841

842

843

844

845

846

847

848

849

850

851

852

853

854

855

856

857

858

859

860

861

862

863

864

865

866

867

868

869

870

871

872

873

874

875
Agana, M., Frueh, J., Kamboj, M., Patel, D.R., and Kanungo, S. (2018). Common metabolic disorder (inborn errors of metabolism) concerns in primary care practice. Ann. Transl. Med. 6, 469-469.

Albright, C.D., Friedrich, C.B., Brown, E.C., Mar, M.H., and Zeisel, S.H. (1999a). Maternal dietary choline availability alters mitosis, apoptosis and the localization of TOAD-64 protein in the developing fetal rat septum. Dev. Brain Res. 115, 123-129.

Albright, C.D., Tsai, A.Y., Friedrich, C.B., Mar, M.-H., and Zeisel, S.H. (1999b). Choline availability alters embryonic development of the hippocampus and septum in the rat. Dev. Brain Res. 113, 13-20.

Angelova, M.T., Dimitrova, D.G., Dinges, N., Lence, T., Worpenberg, L., Carré, C., and Roignant, J.Y. (2018). The emerging field of epitranscriptomics in neurodevelopmental and neuronal disorders. Front. Bioeng. Biotechnol. 6, 46.

Baertling, F., Rodenburg, R.J., Schaper, J., Smeitink, J.A., Koopman, W.J.H., Mayatepek, E., Morava, E., and Distelmaier, F. (2014). A guide to diagnosis and treatment of Leigh syndrome. J. Neurol. Neurosurg. Psychiatry 85, 257-265.

Baertling, F., Klee, D., Haack, T.B., Prokisch, H., Meitinger, T., Mayatepek, E., Schaper, J., and Distelmaier, F. (2016). The many faces of paediatric mitochondrial disease on neuroimaging. Child's Nerv. Syst. 32, 2077-2083.

Barshop, B.A. (2004). Metabolomic approaches to mitochondrial disease: Correlation of urine organic acids. Mitochondrion 4, 521-527.

Bridi, R., Latini, A., Braum, C.A., Zorzi, G.K., Wajner, M., Lissi, E., and Dutra-Filho, C.S. (2005). Evaluation of the mechanisms involved in leucine-induced oxidative damage in cerebral cortex of young rats. Free Radic. Res. 39, 71-79.

Buzkova, J., Nikkanen, J., Ahola, S., Hakonen, A.H., Sevastianova, K., Hovinen, T., Yki-Järvinen, H., Pietiläinen, K.H., Lönnqvist, T., Velagapudi, V., et al. (2018). Metabolomes of mitochondrial diseases and inclusion body myositis patients: treatment targets and biomarkers. EMBO Mol. Med. 10.

Calvo, S., Jain, M., Xie, X., Sheth, S.A., Chang, B., Goldberger, O.A., Spinazzola, A., Zeviani, M., Carr, S.A., and Mootha, V.K. (2006). Systematic identification of human mitochondrial disease genes through integrative genomics. Nat. Genet. 38, 576-582.

Calvo, S.E., Compton, A.G., Hershman, S.G., Lim, S.C., Lieber, D.S., Tucker, E.J., Laskowski, A., Garone, C., Liu, S., Jaffe, D.B., et al. (2012). Molecular diagnosis of infantile mitochondrial disease with targeted next-generation sequencing. Sci. Transl. Med. 4, 118ra10-118ra10.

Camp, J.G., Badsha, F., Florio, M., Kanton, S., Gerber, T., Wilsch-Bräuninger, M., Lewitus, E., Sykes, A., Hevers, W., Lancaster, M., et al. (2015). Human cerebral organoids recapitulate gene expression programs of fetal neocortex development. Proc. Natl. Acad. Sci. 112, 201520760.

Cansev, M. (2006). Uridine and cytidine in the brain: Their transport and utilization. Brain Res. Rev. 52, 389-397.

Cerutti, R., Pirinen, E., Lamperti, C., Marchet, S., Sauve, A.A., Li, W., Leoni, V., Schon, E.A., Dantzer, F., Auwerx, J., et al. (2014). NAD+-dependent activation of Sirt1 corrects the phenotype in a mouse model of mitochondrial disease. Cell Metab. 19, 1042-1049.

Chambers, S.M., Fasano, C.A., Papapetrou, E.P., Tomishima, M., Sadelain, M., and Studer, L. (2009). Highly efficient neural conversion of human ES and iPS cells by dual inhibition of SMAD signaling. Nat. Biotechnol. 27, 275-280.

Chandrasekaran, A., Avci, H.X., Ochalek, A., Rösingh, L.N., Molnár, K., László, L., Bellák, T., Téglási, A., Pesti, K., Mike, A., et al. (2017). Comparison of 2D and 3D neural induction 
908

909

910

911

912

913

914

915

916

917

918

919

920

921

922

923

924

925

926

methods for the generation of neural progenitor cells from human induced pluripotent stem cells. Stem Cell Res. 25, 139-151.

Chen, H., and Chan, D.C. (2017). Mitochondrial Dynamics in Regulating the Unique Phenotypes of Cancer and Stem Cells. Cell Metab. 26, 39-48.

Chong, J., and Xia, J. (2018). MetaboAnalystR: an R package for flexible and reproducible analysis of metabolomics data. Bioinformatics 34, 4313-4314.

Chong, J., Soufan, O., Li, C., Caraus, I., Li, S., Bourque, G., Wishart, D.S., and Xia, J. (2018). MetaboAnalyst 4.0: towards more transparent and integrative metabolomics analysis. Nucleic Acids Res. 46, W486-W494.

Chong, J., Wishart, D.S., and Xia, J. (2019). Using MetaboAnalyst 4.0 for Comprehensive and Integrative Metabolomics Data Analysis. Curr. Protoc. Bioinforma. 68.

Cingolani, P., Patel, V.M., Coon, M., Nguyen, T., Land, S.J., Ruden, D.M., and Lu, X. (2012). Using Drosophila melanogaster as a model for genotoxic chemical mutational studies with a new program, SnpSift. Front. Genet. 3, 35.

Craigen, W.J. (1996). Leigh disease with deficiency of lipoamide dehydrogenase: Treatment failure with dichloroacetate. Pediatr. Neurol. 14, 69-71.

Craven, L., Alston, C.L., Taylor, R.W., and Turnbull, D.M. (2017). Recent Advances in Mitochondrial Disease. Annu. Rev. Genomics Hum. Genet. 18, 257-275.

Cui, Y., Chen, X., Luo, H., Fan, Z., Luo, J., He, S., Yue, H., Zhang, P., and Chen, R. (2016). BioCircos.js: An interactive Circos JavaScript library for biological data visualization on web applications. Bioinformatics 32, 1740-1742.

Das, A.M., Steuerwald, U., and Illsinger, S. (2010). Inborn errors of energy metabolism associated with myopathies. J. Biomed. Biotechnol. 2010.

Diez-Roux, G., Banfi, S., Sultan, M., Geffers, L., Anand, S., Rozado, D., Magen, A., Canidio, E., Pagani, M., Peluso, I., et al. (2011). A high-resolution anatomical atlas of the transcriptome in the mouse embryo. PLoS Biol. 9, e1000582.

Elkabetz, Y., Panagiotakos, G., Al Shamy, G., Socci, N.D., Tabar, V., and Studer, L. (2008). Human ES cell-derived neural rosettes reveal a functionally distinct early neural stem cell stage. Genes Dev. 22, 152-165.

Esterhuizen, K., van der Westhuizen, F.H., and Louw, R. (2017). Metabolomics of mitochondrial disease. Mitochondrion 35, 97-110.

Fang, Q., Zhang, Y., Chen, X., Li, H., Cheng, L., Zhu, W., Zhang, Z., Tang, M., Liu, W., Wang, $\mathrm{H}$., et al. (2020). Three-Dimensional Graphene Enhances Neural Stem Cell Proliferation Through Metabolic Regulation. Front. Bioeng. Biotechnol. 7, 436.

Feeney, C.L., Lim, A.Z., Fagan, E., Blain, A., Bright, A., Maddison, J., Devine, H., Stewart, J., Taylor, R.W., Gorman, G.S., et al. (2019). A case-comparison study of pregnant women with mitochondrial disease - what to expect? BJOG An Int. J. Obstet. Gynaecol. 126, 1380-1389.

Ferlin, T., Landrieu, P., Rambaud, C., Fernandez, H., Dumoulin, R., Rustin, P., and Mousson, B. (1997). Segregation of the G8993 mutant mitochondrial DNA through generations and embryonic tissues family at risk of Leigh syndrome. J. Pediatr. 131, 447-449.

Ferrari, M., Jain, I.H., Goldberger, O., Rezoagli, E., Thoonen, R., Chen, K.-H., Sosnovik, D.E., Scherrer-Crosbie, M., Mootha, V.K., and Zapol, W.M. (2017). Hypoxia treatment reverses neurodegenerative disease in a mouse model of Leigh syndrome. Proc. Natl. Acad. Sci. 114, E4241-E4250.

Ferreira, G.C., and McKenna, M.C. (2017). I-Carnitine and Acetyl-I-carnitine Roles and Neuroprotection in Developing Brain. Neurochem. Res. 42, 1661-1675.

Finsterer, J. (2008). Leigh and Leigh-Like Syndrome in Children and Adults. Pediatr. Neurol. 39, 223-235.

Florio, M., and Huttner, W.B. (2014). Neural progenitors, neurogenesis and the evolution of the neocortex. Development 141, 2182-2194. 
961

962

963

964

965

966

967

968

969

970

971

972

973

974

975

976

977

Galera-Monge, T., Zurita-Díaz, F., González-Páramos, C., Moreno-Izquierdo, A., Fraga, M.F., Fernández, A.F., Garesse, R., and Gallardo, M.E. (2016). Generation of a human iPSC line from a patient with Leigh syndrome caused by a mutation in the MT-ATP6 gene. Stem Cell Res. 16, 766-769.

García-Cazorla, A., Oyarzabal, A., Fort, J., Robles, C., Castejón, E., Ruiz-Sala, P., Bodoy, S., Merinero, B., Lopez-Sala, A., Dopazo, J., et al. (2014). Two Novel Mutations in the BCKDK (Branched-Chain Keto-Acid Dehydrogenase Kinase) Gene Are Responsible for a Neurobehavioral Deficit in Two Pediatric Unrelated Patients. Hum. Mutat. 35, 470-477.

Gerards, M., Sallevelt, S.C.E.H., and Smeets, H.J.M. (2016). Leigh syndrome: Resolving the clinical and genetic heterogeneity paves the way for treatment options. Mol. Genet. Metab. 117, 300-312.

Gogos, J.A., Santha, M., Takacs, Z., Beck, K.D., Luine, V., Lucas, L.R., Nadler, J.V., and Karayiorgou, M. (1999). The gene encoding proline dehydrogenase modulates sensorimotor gating in mice. Nat. Genet. 21, 434-439.

Gorman, G.S., Chinnery, P.F., DiMauro, S., Hirano, M., Koga, Y., McFarland, R., Suomalainen, A., Thorburn, D.R., Zeviani, M., and Turnbull, D.M. (2016). Mitochondrial diseases. Nat. Rev. Dis. Prim. 2, 1-22.

Grace, H.E., Galdun, P., Lesnefsky, E.J., West, F.D., and lyer, S. (2019). MRNA Reprogramming of T8993G Leigh's Syndrome Fibroblast Cells to Create Induced Pluripotent Stem Cell Models for Mitochondrial Disorders. Stem Cells Dev. 28, 846-859.

Grier, J., Hirano, M., Karaa, A., Shepard, E., and Thompson, J.L.P. (2018). Diagnostic odyssey of patients with mitochondrial disease Results of a survey. Neurol. Genet. 4.

Harding, A.E., Holt, I.J., Sweeney, M.G., Brockington, M., and Davis, M.B. (1992). Prenatal diagnosis of mitochondrial DNA8993 T $\rightarrow$ G disease. Am. J. Hum. Genet. 50, 629-633.

Hattori, T., Hamazaki, T., Kudo, S., and Shintaku, H. (2016). Metabolic Signature of MELAS/Leigh Overlap Syndrome in Patient-specific Induced Pluripotent Stem Cells Model. Osaka City Med. J. 62, 69-76.

Hinman, L.M., Sheu, K.-F.R., Baker, A.C., Kim, Y.T., and Blass, J.P. (1989). Deficiency of pyruvate dehydrogenase complex (PDHC) in Leigh's disease fibroblasts: An abnormality in lipoamide dehydrogenase affecting PDHC activation. Neurology 39, 70-70.

Homem, C.C.F., Repic, M., and Knoblich, J.A. (2015). Proliferation control in neural stem and progenitor cells. Nat. Rev. Neurosci. 16, 647-659.

Hríbková, H., Grabiec, M., Klemová, D., Slaninová, I., and Sun, Y.-M. (2018). Five steps to form neural rosettes: structure and function. J. Cell Sci. 131, jcs206896.

Huh, T.L., Casazza, J.P., Huh, J.W., Chi, Y.T., and Song, B.J. (1990). Characterization of two cDNA clones for pyruvate dehydrogenase $E 1 \beta$ subunit and its regulation in tricarboxylic acid cycle-deficient fibroblast. J. Biol. Chem. 265, 13320-13326.

Inak, G., Lorenz, C., Lisowski, P., Zink, A., Mlody, B., and Prigione, A. (2017). Concise Review: Induced Pluripotent Stem Cell-Based Drug Discovery for Mitochondrial Disease. Stem Cells 35, 1655-1662.

Inak, G., Rybak-Wolf, A., Lisowski, P., Juettner, R., Zink, A., Mlody, B., Glazar, P., Secker, C., Ciptasari, U.H., Stenzel, W., et al. (2019). SURF1 mutations causative of Leigh syndrome impair human neurogenesis. BioRxiv 551390.

Itskovitz-Eldor, J., Schuldiner, M., Karsenti, D., Eden, A., Yanuka, O., Amit, M., Soreq, H., and Benvenisty, N. (2000). Differentiation of Human Embryonic Stem Cells into Embryoid Bodies Comprising the Three Embryonic Germ Layers. Mol. Med. 6, 88-95.

lyer, S., Bergquist, K., Young, K., Gnaiger, E., Rao, R.R., and Bennett, J.P. (2012). Mitochondrial Gene Therapy Improves Respiration, Biogenesis, and Transcription in G11778A Leber's Hereditary Optic Neuropathy and T8993G Leigh's Syndrome Cells. Hum. Gene Ther. 23, 647-657.

Jain, I.H., Zazzeron, L., Goli, R., Alexa, K., Schatzman-Bone, S., Dhillon, H., Goldberger, O., 
1011

1012

1013

1014

1015

1016

1017

1018

1019

1020

1021

1022

1023

1024

1025

1026

1027

1028

Peng, J., Shalem, O., Sanjana, N.E., et al. (2016). Hypoxia as a therapy for mitochondrial disease. Science (80-. ). 352, 54-61.

Jain, I.H., Zazzeron, L., Goldberger, O., Marutani, E., Wojtkiewicz, G.R., Ast, T., Wang, H., Schleifer, G., Stepanova, A., Brepoels, K., et al. (2019). Leigh Syndrome Mouse Model Can Be Rescued by Interventions that Normalize Brain Hyperoxia, but Not HIF Activation. Cell Metab. 0, 824-832.e3.

Jernberg, J.N., Bowman, C.E., Wolfgang, M.J., and Scafidi, S. (2017). Developmental regulation and localization of carnitine palmitoyltransferases (CPTs) in rat brain. J. Neurochem. 142, 407-419.

Kelava, I., and Lancaster, M.A. (2016). Stem Cell Models of Human Brain Development. Cell Stem Cell 18, 736-748.

Khacho, M., Clark, A., Svoboda, D.S., Azzi, J., MacLaurin, J.G., Meghaizel, C., Sesaki, H., Lagace, D.C., Germain, M., Harper, M.E., et al. (2016). Mitochondrial Dynamics Impacts Stem Cell Identity and Fate Decisions by Regulating a Nuclear Transcriptional Program. Cell Stem Cell.

Lake, N.J., Bird, M.J., Isohanni, P., and Paetau, A. (2015). Leigh syndrome: neuropathology and pathogenesis. J. Neuropathol. Exp. Neurol. 74, 482-492.

Lake, N.J., Compton, A.G., Rahman, S., and Thorburn, D.R. (2016). Leigh syndrome: One disorder, more than 75 monogenic causes. Ann. Neurol. 79, 190-203.

Lancaster, M.A., and Knoblich, J.A. (2014). Generation of cerebral organoids from human pluripotent stem cells. Nat. Protoc. 9, 2329-2340.

Lancaster, M.A., Corsini, N.S., Wolfinger, S., Gustafson, E.H., Phillips, A.W., Burkard, T.R., Otani, T., Livesey, F.J., and Knoblich, J.A. (2017). Guided self-organization and cortical plate formation in human brain organoids. Nat. Publ. Gr. 35.

Leigh, D. (1951). Subacute necrotizing encephalomyelopathy in an infant. J. Neurol. Neurosurg. Psychiatry 14, 216-221.

Lorenz, C., Lesimple, P., Bukowiecki, R., Zink, A., Inak, G., Mlody, B., Singh, M., Semtner, M., Mah, N., Auré, K., et al. (2017). Human iPSC-Derived Neural Progenitors Are an Effective Drug Discovery Model for Neurological mtDNA Disorders. Cell Stem Cell 20, 659-674.e9.

Lui, J.H., Hansen, D. V., and Kriegstein, A.R. (2011). Development and evolution of the human neocortex. Cell 146, 18-36.

Di Lullo, E., and Kriegstein, A.R. (2017). The use of brain organoids to investigate neural development and disease. Nat. Rev. Neurosci. 18, 573-584.

Ma, H., Folmes, C.D.L., Wu, J., Morey, R., Mora-Castilla, S., Ocampo, A., Ma, L., Poulton, J., Wang, X., Ahmed, R., et al. (2015). Metabolic rescue in pluripotent cells from patients with mtDNA disease. Nature 524, 234-238.

Manoli, I., and Venditti, C.P. (2016). Disorders of branched chain amino acid metabolism. Transl. Sci. Rare Dis. 1, 91-110.

Mathieu, J., and Ruohola-Baker, H. (2017). Metabolic remodeling during the loss and acquisition of pluripotency. Dev. 144, 541-551.

Medelnik, J.-P., Roensch, K., Okawa, S., del Sol, A., Chara, O., Mchedlishvili, L., and Tanaka, E.M. (2018). Signaling-Dependent Control of Apical Membrane Size and Self-Renewal in Rosette-Stage Human Neuroepithelial Stem Cells. Stem Cell Reports 10, 1751-1765.

Di Meo, I., Marchet, S., Lamperti, C., Zeviani, M., and Viscomi, C. (2017). AAV9-based gene therapy partially ameliorates the clinical phenotype of a mouse model of Leigh syndrome. Gene Ther. 24, 661-667.

Miyabayashi, S., Ito, T., Narisawa, K., linuma, K., and Tada, K. (1985). Biochemical study in 28 children with lactic acidosis, in relation to Leigh's encephalomyelopathy. Eur. J. Pediatr. 143, 278-283.

Müller, F.J., Schuldt, B.M., Williams, R., Mason, D., Altun, G., Papapetrou, E.P., Danner, S., Goldmann, J.E., Herbst, A., Schmidt, N.O., et al. (2011). A bioinformatic assay for 
1058

1059

1060

1061

1062

1063

1064

1065

1066

1067

1068

1069

1070

1071

1072

1073

1074

1075

1076

1077

1078

1079 pluripotency in human cells. Nat. Methods 8, 315-317.

Muratore, C.R., Srikanth, P., Callahan, D.G., and Young-Pearse, T.L. (2014). Comparison and optimization of hiPSC forebrain cortical differentiation protocols. PLoS One 9, e105807.

Nakano, C., Takashima, S., and Takeshita, K. (1989). Carnitine concentration during the development of human tissues. Early Hum. Dev. 19, 21-27.

Nesbitt, V., Alston, C.L., Blakely, E.L., Fratter, C., Feeney, C.L., Poulton, J., Brown, G.K., Turnbull, D.M., Taylor, R.W., and McFarland, R. (2014). A national perspective on prenatal testing for mitochondrial disease. Eur. J. Hum. Genet. 22, 1255-1259.

Oshida, K., Shimizu, T., Takase, M., Tamura, Y., Shimizu, T., and Yamashiro, Y. (2003). Effects of dietary sphingomyelin on central nervous system myelination in developing rats. Pediatr. Res. 53, 589-593.

Pampaloni, F., Reynaud, E.G., and Stelzer, E.H.K. (2007). The third dimension bridges the gap between cell culture and live tissue. Nat. Rev. Mol. Cell Biol. 8, 839-845.

Panopoulos, A.D., Yanes, O., Ruiz, S., Kida, Y.S., Diep, D., Tautenhahn, R., Herrerías, A., Batchelder, E.M., Plongthongkum, N., Lutz, M., et al. (2012). The metabolome of induced pluripotent stem cells reveals metabolic changes occurring in somatic cell reprogramming. Cell Res. 22, 168-177.

Parikh, S., Goldstein, A., Karaa, A., Koenig, M.K., Anselm, I., Brunel-Guitton, C., Christodoulou, J., Cohen, B.H., Dimmock, D., Enns, G.M., et al. (2017). Patient care standards for primary mitochondrial disease: A consensus statement from the mitochondrial medicine society. Genet. Med. 19, 1-18.

Paşca, A.M., Sloan, S.A., Clarke, L.E., Tian, Y., Makinson, C.D., Huber, N., Kim, C.H., Park, J.Y., O'Rourke, N.A., Nguyen, K.D., et al. (2015). Functional cortical neurons and astrocytes from human pluripotent stem cells in 3D culture. Nat Methods. 12, 671-678.

Pastores, G.M., Santorelli, F.M., Shanske, S., Gelb, B.D., Fyfe, B., Wolfe, D., and Willner, J.P. (1994). Leigh syndrome and hypertrophic cardiomyopathy in an infant with a mitochondrial DNA point mutation (T8993G). Am. J. Med. Genet. 50, 265-271.

Quadrato, G., Brown, J., and Arlotta, P. (2016). The promises and challenges of human brain organoids as models of neuropsychiatric disease. Nat. Med. 22, 1220-1228.

Rahman, J., and Rahman, S. (2018). Mitochondrial medicine in the omics era. Lancet 391, 2560-2574.

Rasmussen, M.L., and Gama, V. (2020). A connection in life and death: The BCL-2 family coordinates mitochondrial network dynamics and stem cell fate. In International Review of Cell and Molecular Biology, (Elsevier Inc.), p.

Rastogi, A., Joshi, P., Contreras, E., and Gama, V. (2019). Remodeling of mitochondrial morphology and function: an emerging hallmark of cellular reprogramming. Cell Stress 3, 181-194.

Rema, V., Bali, K.K., Ramachandra, R., Chugh, M., Darokhan, Z., and Chaudhary, R. (2008). Cytidine-5-diphosphocholine supplement in early life induces stable increase in dendritic complexity of neurons in the somatosensory cortex of adult rats. Neuroscience $155,556-$ 564.

Robel, S., Mori, T., Zoubaa, S., Schlegel, J., Sirko, S., Faissner, A., Goebbels, S., Dimou, L., and Götz, M. (2009). Conditional deletion of $\beta 1$-integrin in astroglia causes partial reactive gliosis. Glia 57, 1630-1647.

Robel, S., Berninger, B., and Götz, M. (2011). The stem cell potential of glia: Lessons from reactive gliosis. Nat. Rev. Neurosci. 12, 88-104.

Romero-Morales, A.I., O'Grady, B.J., Balotin, K.M., Bellan, L.M., Lippmann, E.S., and Gama, V. (2019). Spin $\infty$ an improved miniaturized spinning bioreactor for the generation of human cerebral organoids from pluripotent stem cells. BioRxiv 687095.

Saito, T., Hanai, S., Takashima, S., Nakagawa, E., Okazaki, S., Inoue, T., Miyata, R., Hoshino, K., Akashi, T., Sasaki, M., et al. (2011). Neocortical layer formation of human developing 
1080

1081

1082

1083

1084

1085

1086

1087

1088

1089

1090

1091

1092

1093

1094

1095

1096

1097

1098

1099

1100

1101

1102

1103

1104

1105

1106

1107

1108

1109

1110

1111

1112

1113

1114

1115

1116

1117

1118

1119

1120

1121

1122

1123

1124

1125

1126

1127

1128

1129

1130

brains and lissencephalies: Consideration of layer-specific marker expression. Cereb. Cortex 21, 588-596.

Schaefer, A., Lim, A., and Gorman, G. (2019). Epidemiology of Mitochondrial Disease. In Diagnosis and Management of Mitochondrial Disorders, (Cham: Springer International Publishing), pp. 63-79.

Schubert, M.B., and Vilarinho, L. (2020). Molecular basis of Leigh syndrome: A current look. Orphanet J. Rare Dis. 15, 1-14.

Shaheen, R., Han, L., Faqeih, E., Ewida, N., Alobeid, E., Phizicky, E.M., and Alkuraya, F.S. (2016). A homozygous truncating mutation in PUS3 expands the role of tRNA modification in normal cognition. Hum. Genet. 135, 707-713.

Song, C., Xu, F., Ren, Z., Zhang, Y., Meng, Y., Yang, Y., Lingadahalli, S., Cheung, E., Li, G., Liu, W., et al. (2019). Elevated Exogenous Pyruvate Potentiates Mesodermal Differentiation through Metabolic Modulation and AMPK/mTOR Pathway in Human Embryonic Stem Cells. Stem Cell Reports 13, 338-351.

Sorbi, S., and Blass, J.P. (1982). Abnormal activation of pyruvate dehydrogenase in Leigh disease fibroblasts. Neurology 32, 555-558.

Steffann, J., Gigarel, N., Corcos, J., Bonnière, M., Encha-Razavi, F., Sinico, M., Prevot, S., Dumez, Y., Yamgnane, A., Frydman, R., et al. (2007). Stability of the m.8993T $\rightarrow$ G mtDNA mutation load during human embryofetal development has implications for the feasibility of prenatal diagnosis in NARP syndrome. J. Med. Genet. 44, 664-669.

Stern, H.J. (1994). Lactic acidosis in paediatrics: Clinical and laboratory evaluation. Ann. Clin. Biochem. 31, 410-419.

Takahashi, K., Tanabe, K., Ohnuki, M., Narita, M., Ichisaka, T., Tomoda, K., and Yamanaka, S. (2007). Induction of Pluripotent Stem Cells from Adult Human Fibroblasts by Defined Factors. Cell 131, 861-872.

TCW, J., Wang, M., Pimenova, A.A., Bowles, K.R., Hartley, B.J., Lacin, E., Machlovi, S.I., Abdelaal, R., Karch, C.M., Phatnani, H., et al. (2017). An Efficient Platform for Astrocyte Differentiation from Human Induced Pluripotent Stem Cells. Stem Cell Reports 9, 600614.

Tibbitt, M.W., and Anseth, K.S. (2012). Dynamic microenvironments: The fourth dimension. Sci. Transl. Med. 4, 160ps24-160ps24.

Uittenbogaard, M., Brantner, C.A., Fang, Z.S., Wong, L.J.C., Gropman, A., and Chiaramello, A. (2018). Novel insights into the functional metabolic impact of an apparent de novo m.8993T>G variant in the MT-ATP6 gene associated with maternally inherited form of Leigh Syndrome. Mol. Genet. Metab. 124, 71-81.

Vescovi, A.L., and Snyder, E.Y. (1999). Establishment and properties of neural stem cell clones: Plasticity in vitro and in vivo. In Brain Pathology, (International Society of Neuropathology), pp. 569-598.

Vorstman, J.A.S., Turetsky, B.I., Sijmens-Morcus, M.E.J., De Sain, M.G., Dorland, B., Sprong, M., Rappaport, E.F., Beemer, F.A., Emanuel, B.S., Kahn, R.S., et al. (2009). Proline affects brain function in 22q11DS children with the low activity COMT158 allele. Neuropsychopharmacology 34, 739-746.

White, S.L., Collins, V.R., Wolfe, R., Cleary, M.A., Shanske, S., DiMauro, S., Dahl, H.H.M., and Thorburn, D.R. (1999). Genetic counseling and prenatal diagnosis for the mitochondrial DNA mutations at nucleotide 8993. Am. J. Hum. Genet. 65, 474-482.

Wilson, P.G., and Stice, S.S. (2006). Development and differentiation of neural rosettes derived from human embryonic stem cells. Stem Cell Rev. 2, 67-77.

Wu, J., Ocampo, A., and Belmonte, J.C.I. (2016). Cellular Metabolism and Induced Pluripotency. Cell 166, 1371-1385.

Xia, J., and Wishart, D.S. (2010). MetPA: a web-based metabolomics tool for pathway analysis and visualization. Bioinformatics 26, 2342-2344. 
Xia, J., and Wishart, D.S. (2011a). Metabolomic data processing, analysis, and interpretation using MetaboAnalyst. Curr. Protoc. Bioinforma. 34, 1-48.

Xia, J., and Wishart, D.S. (2011b). Web-based inference of biological patterns, functions and pathways from metabolomic data using MetaboAnalyst. Nat. Protoc. 6, 743-760.

Xia, J., Psychogios, N., Young, N., and Wishart, D.S. (2009). MetaboAnalyst: a web server for metabolomic data analysis and interpretation. Nucleic Acids Res. 37, W652-W660.

Zanotelli, M.R., Goldblatt, Z.E., Miller, J.P., Bordeleau, F., Li, J., VanderBurgh, J.A., Lampi, M.C., King, M.R., and Reinhart-King, C.A. (2018). Regulation of ATP utilization during metastatic cell migration by collagen architecture. Mol. Biol. Cell 29, 1-9.

Zanotelli, M.R., Rahman-Zaman, A., VanderBurgh, J.A., Taufalele, P. V., Jain, A., Erickson, D., Bordeleau, F., and Reinhart-King, C.A. (2019). Energetic costs regulated by cell mechanics and confinement are predictive of migration path during decision-making. Nat. Commun. 10, 1-12.

Zeisel, S.H. (2006). The fetal origins of memory: The role of dietary choline in optimal brain development. J. Pediatr. 149, S131-S136.

Zeisel, S.H., and Niculescu, M.D. (2006). Perinatal Choline Influences Brain Structure and Function. Nutr. Rev. 64, 197-203.

Zhang, S.-C., Wernig, M., Duncan, I.D., Brüstle, O., and Thomson, J.A. (2001). In vitro differentiation of transplantable neural precursors from human embryonic stem cells. Nat. Biotechnol. 19, 1129-1133. 
Figure 1

bioRxiv preprint doi: https://doi.org/10.1101/2020.04.21.054361; this version posted March 11, 2021. The copyright holder for this preprint (which was not certified by peer review) is the author/funder, who has granted bioRxiv a license to display the preprint in perpetuity. It is made available under aCC-BY-NC-ND 4.0 International license.

A

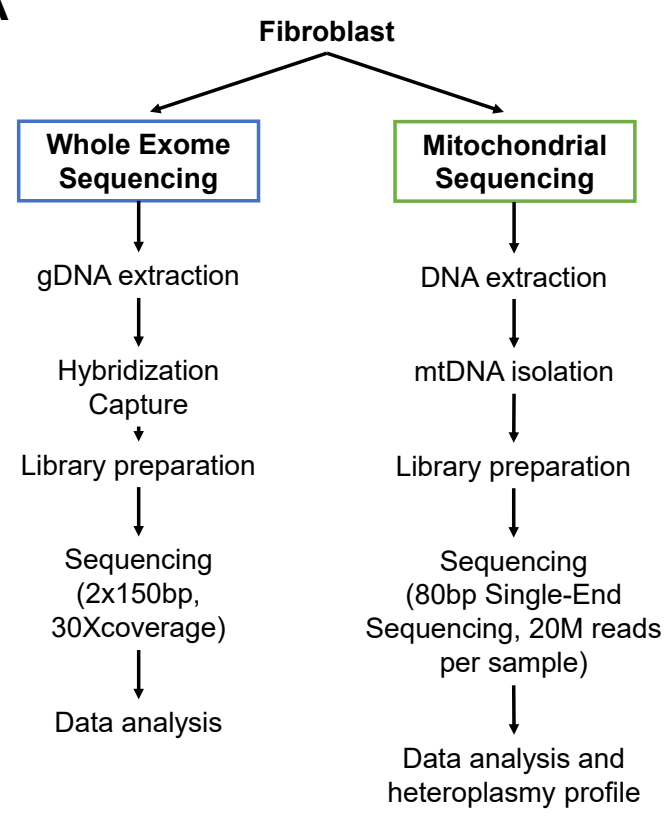

C

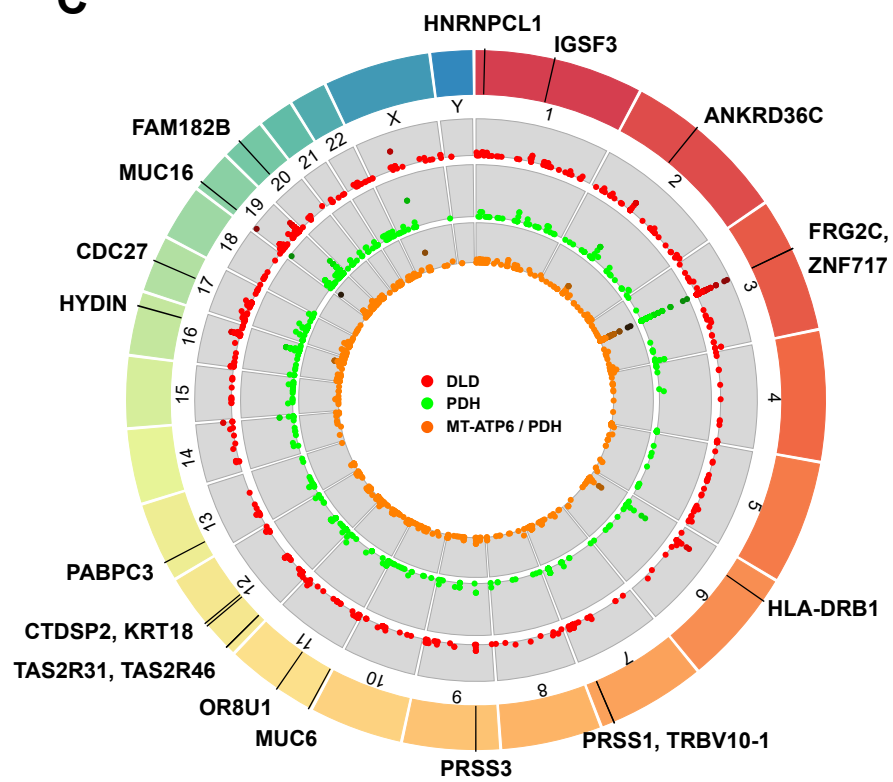

B

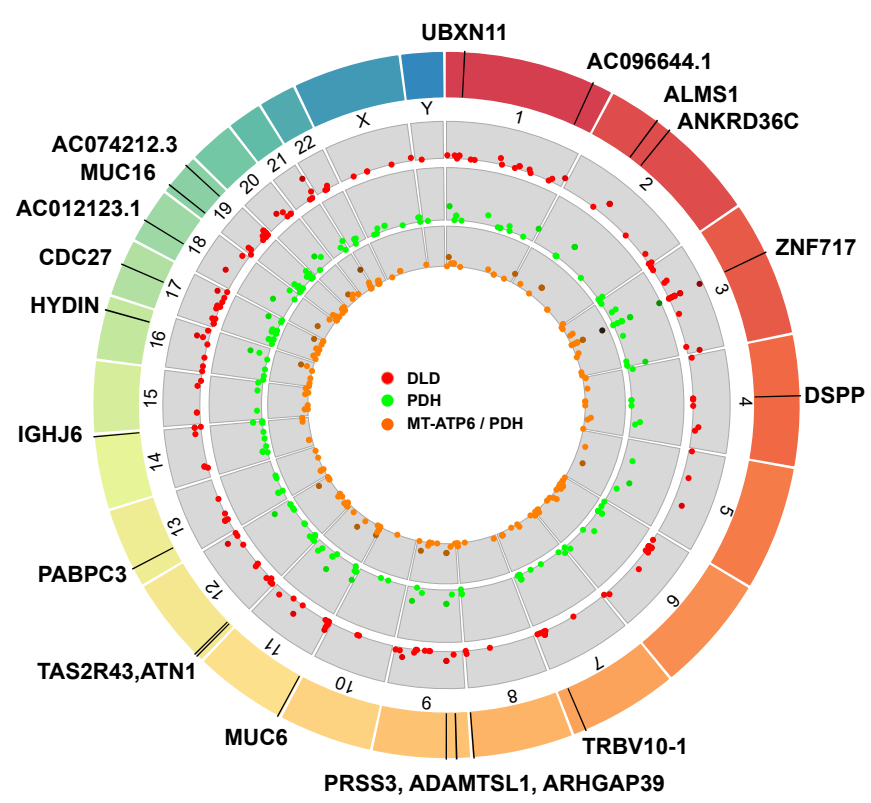

D

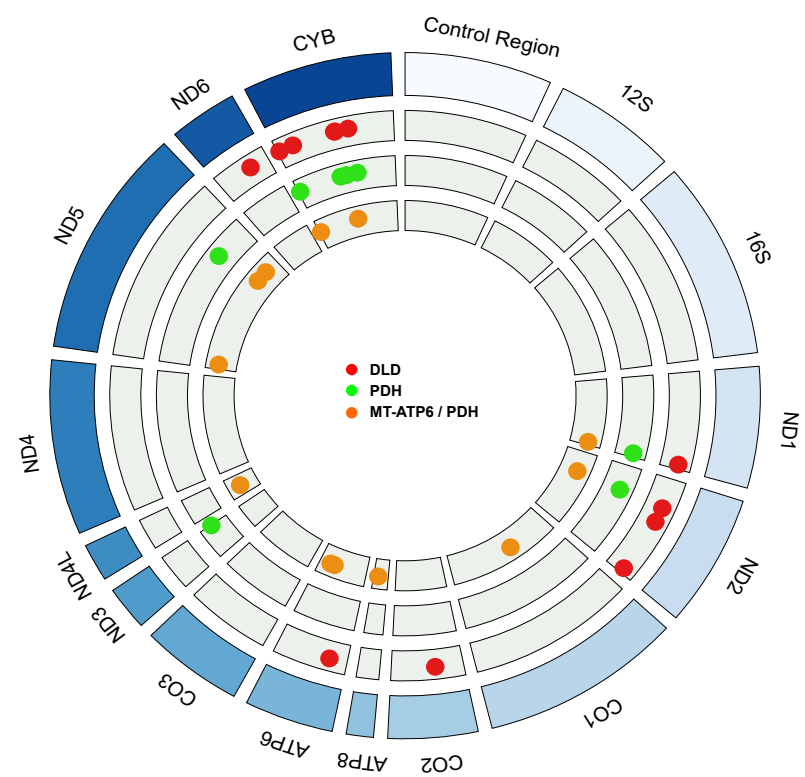


Figure 2

bioRxiv preprint doi: https://doi.org/10.1101/2020.04.21.054361; this version posted March 11, 2021. The copyright holder for this preprint A (which was not certified by peer review) is the author/funder, who has granted bioRxiv a license to display the preprint in perpetuity. It is made

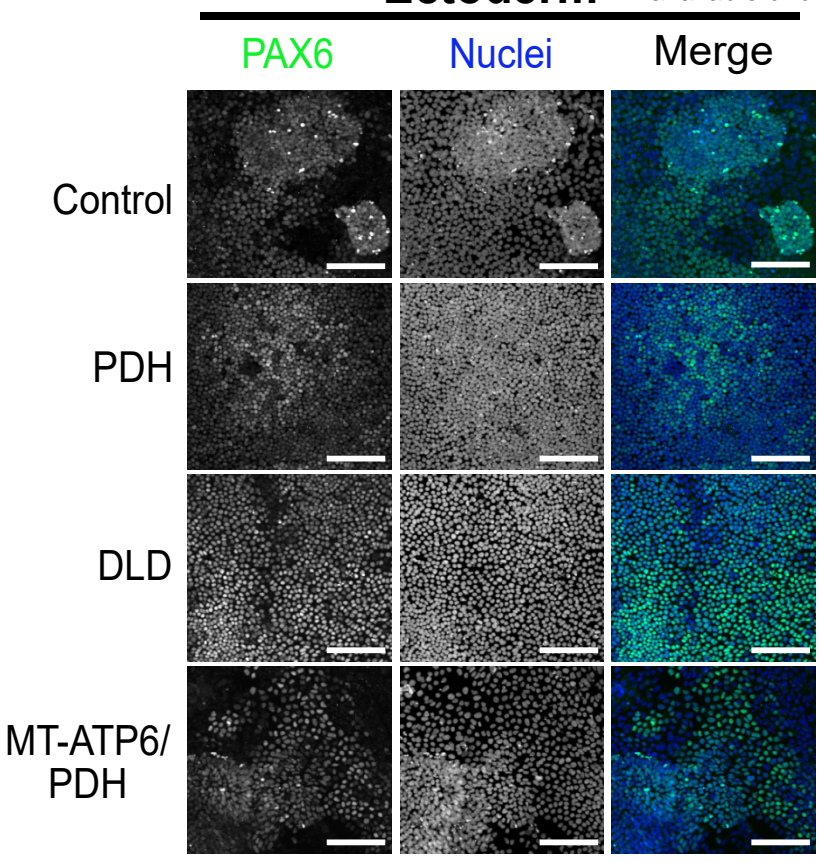

B

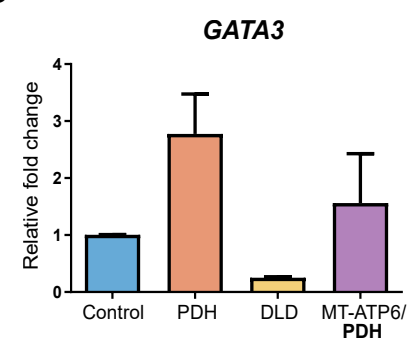

E

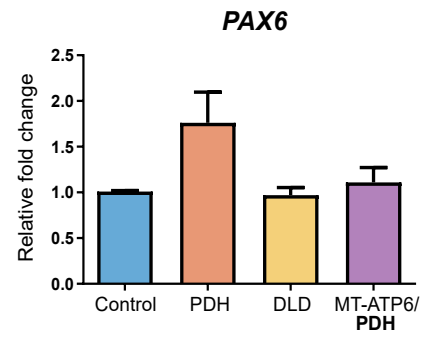

Mesoderm

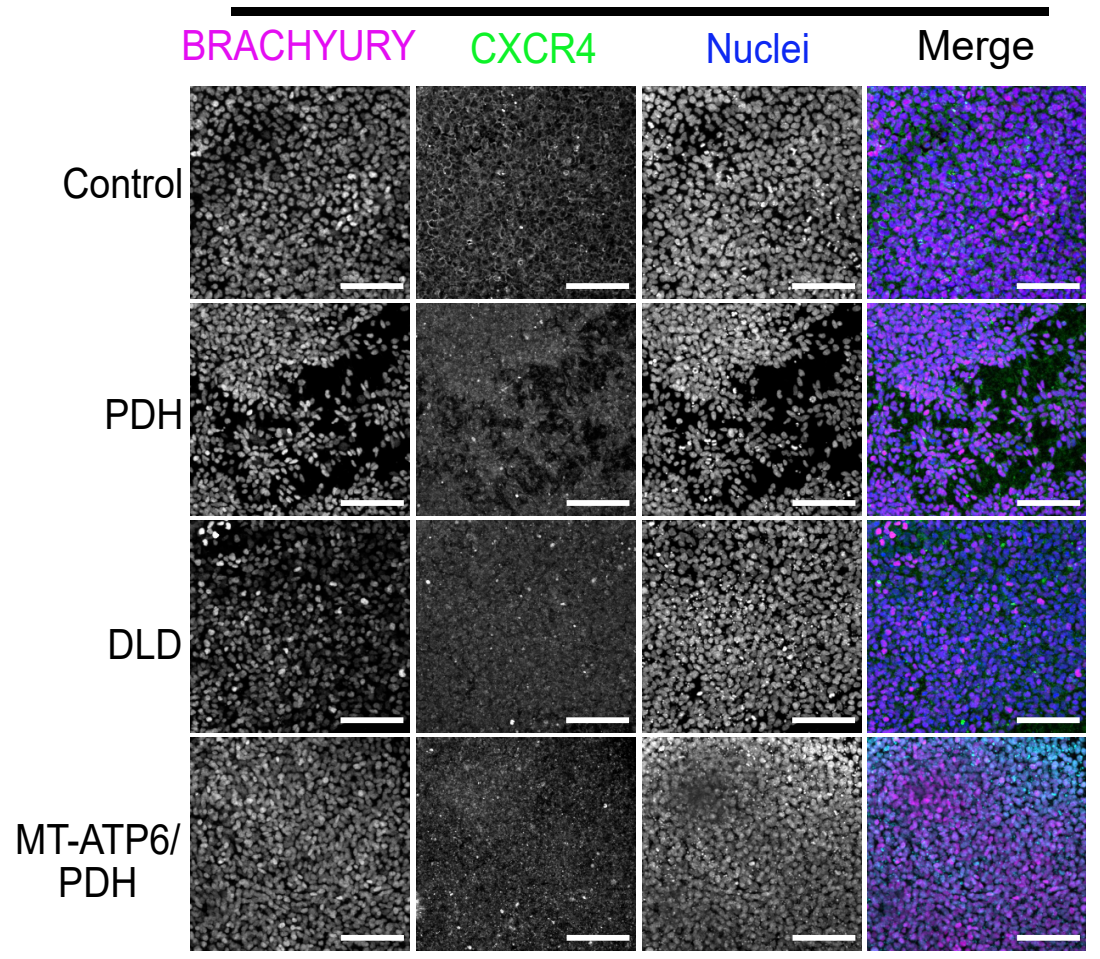

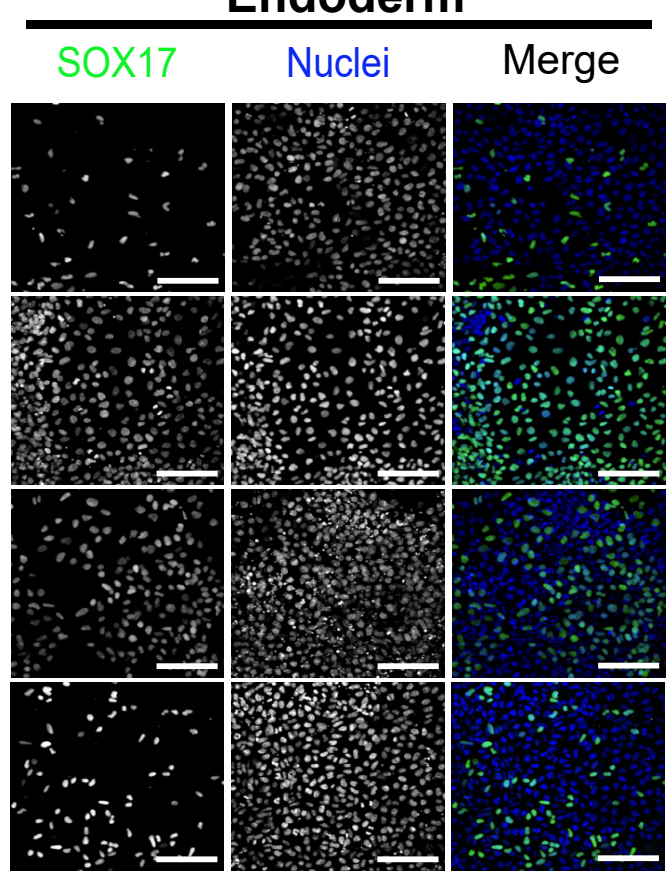
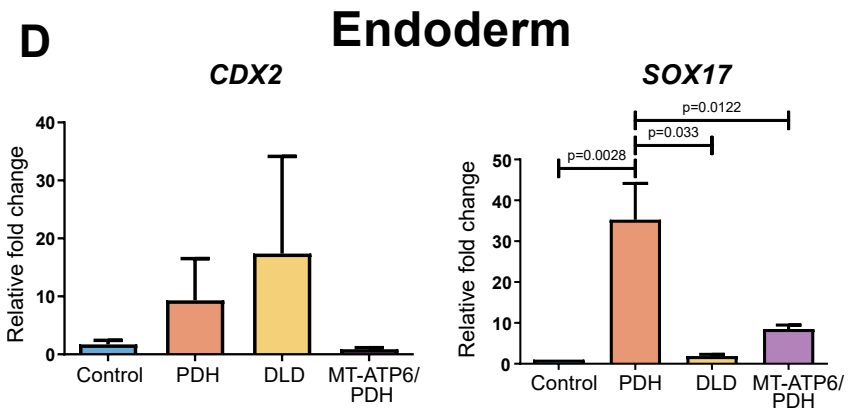

$\mathbf{F}$

Mesoderm
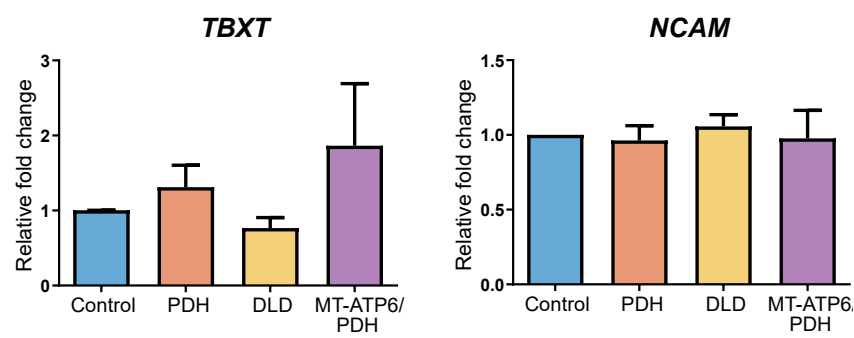
Figure 3

bioRxiv preprint doi: https://doi.org/10.1101/2020.04.21.054361; this version posted March 11, 2021. The copyright holder for this preprint (which was not certified by peer review) is the author/funder, who has granted bioRxiv a license to display the preprint in perpetuity. It is made

A available under aCC-BY-NC-ND 4.0 inter

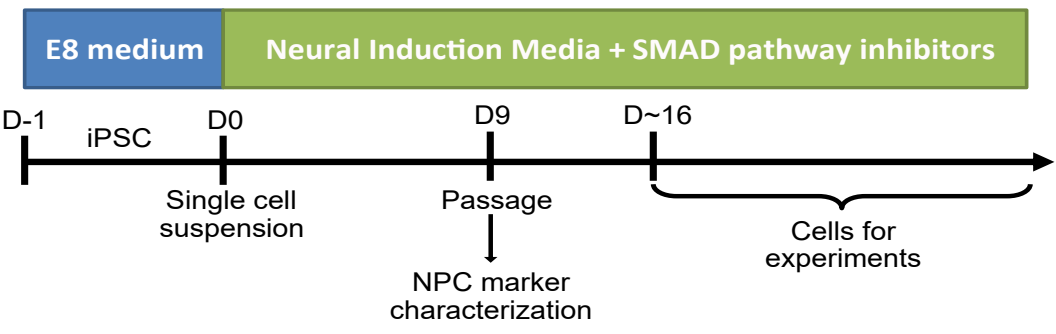

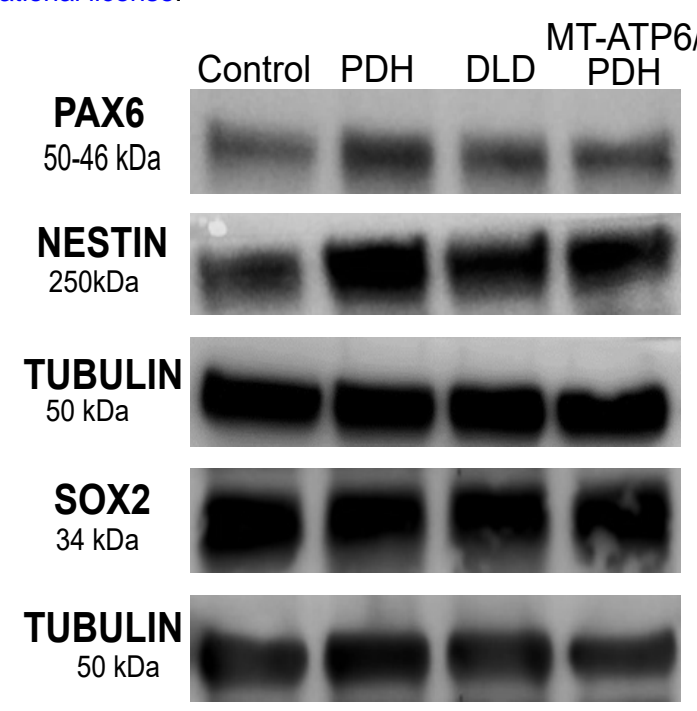
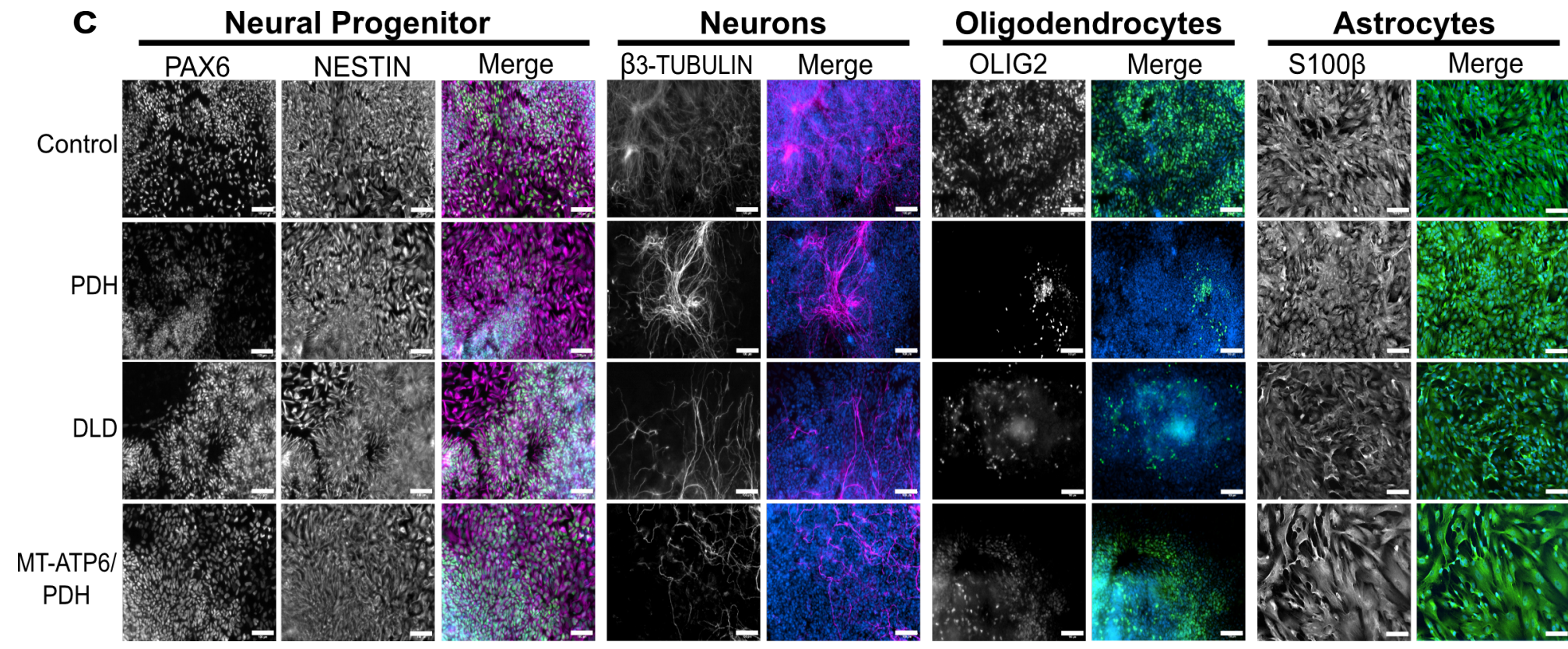

D

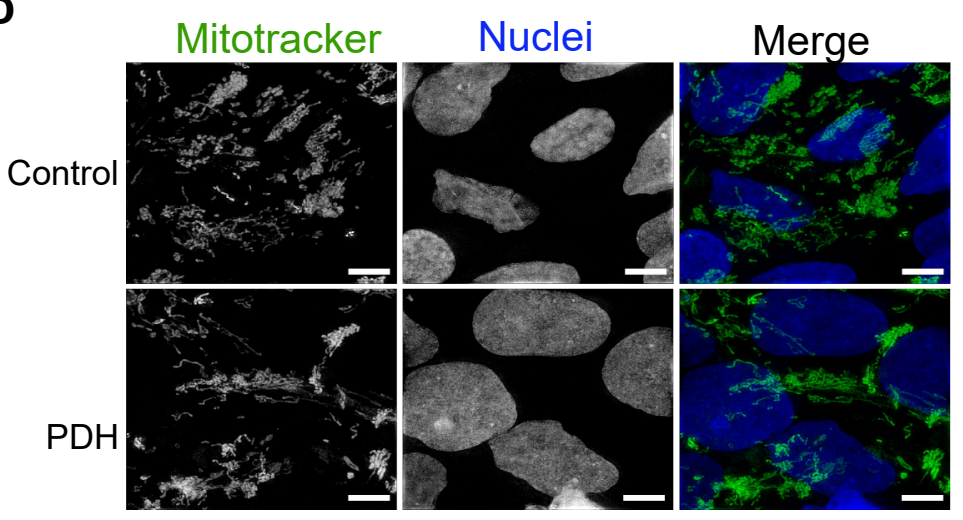

MT-ATP6/ $\mathrm{PDH}$

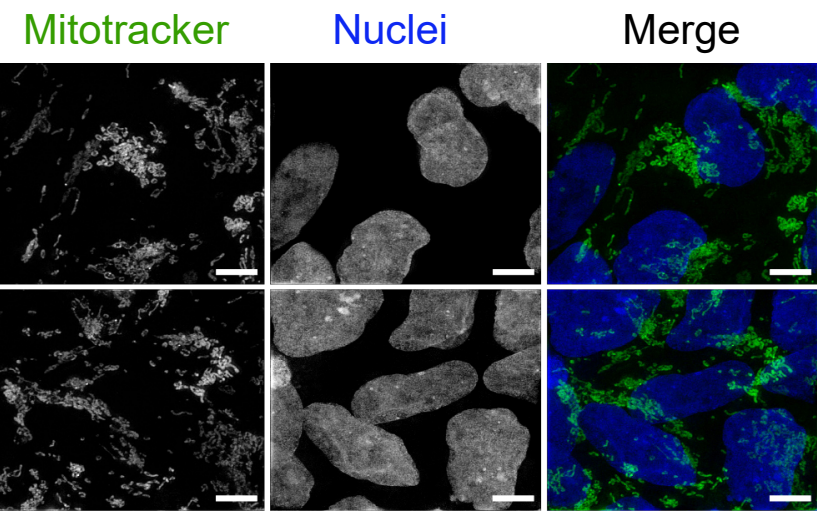


Figure 4

bioRxiv preprint doi: https://doi.org/10.1101/2020.04.21.054361; this version posted March 11, 2021. The copyright holder for this preprint (which was not certified by peer review) is the author/funder, who has granted bioRxiv a license to display the preprint in perpetuity. It is made available under aCC-BY-NC-ND 4.0 International license.

A

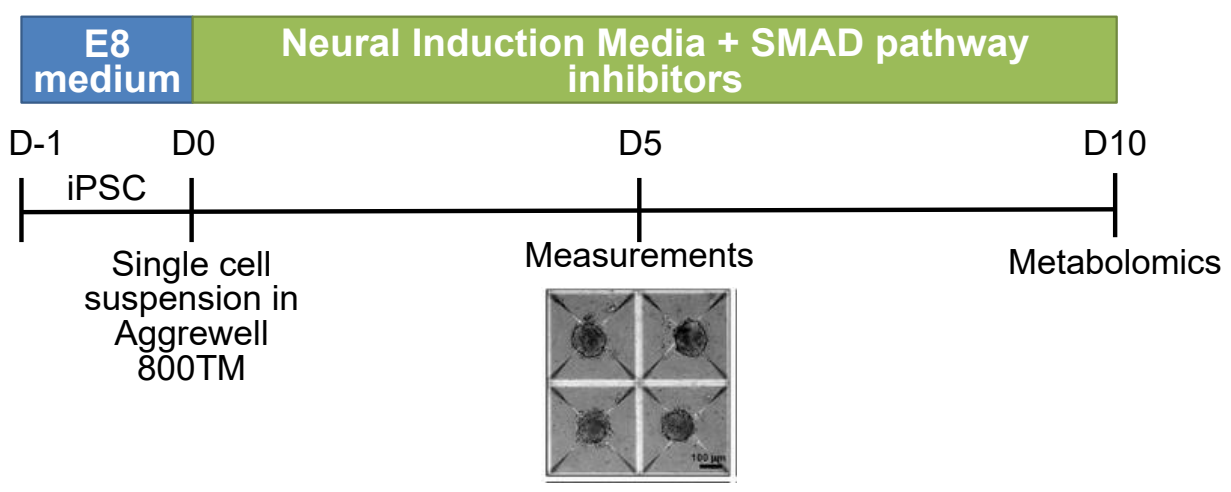

B

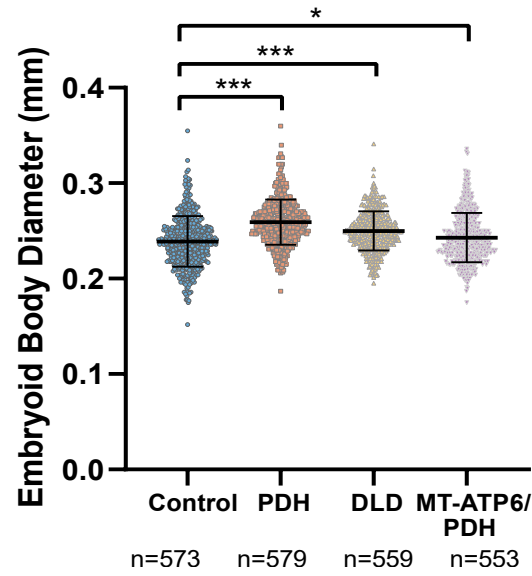

C

\begin{tabular}{l|c|c|c|c|c|c|c}
\hline \multicolumn{1}{c|}{ Pathway } & Hits & Total & Raw $\mathbf{p}$ & -log(p) & Holm adjust & FDR & Impact \\
\hline Alanine, aspartate and glutamate metabolism & 16 & 28 & $9.88 \mathrm{E}-13$ & 27.643 & $8.30 \mathrm{E}-11$ & $8.30 \mathrm{E}-11$ & 0.76282 \\
\hline Synthesis and degradation of ketone bodies & 1 & 5 & 0.29616 & 1.2169 & 1 & 0.85783 & 0.6 \\
\hline Arginine biosynthesis & 9 & 14 & $3.24 \mathrm{E}-08$ & 17.244 & $2.69 \mathrm{E}-06$ & $1.36 \mathrm{E}-06$ & 0.5736 \\
\hline Glycine, serine and threonine metabolism & 8 & 33 & 0.001137 & 6.7797 & 0.088659 & 0.01364 & 0.55868 \\
\hline D-Glutamine and D-glutamate metabolism & 3 & 6 & 0.005201 & 5.259 & 0.38485 & 0.036405 & 0.5 \\
\hline Cysteine and methionine metabolism & 9 & 33 & 0.000209 & 8.4735 & 0.016923 & 0.003721 & 0.47436 \\
\hline Nicotinate and nicotinamide metabolism & 4 & 15 & 0.015176 & 4.188 & 1 & 0.091058 & 0.42895 \\
\hline Beta-Alanine metabolism & 2 & 21 & 0.42186 & 0.86309 & 1 & 1 & 0.39925 \\
\hline Pyrimidine metabolism & 14 & 39 & $6.64 \mathrm{E}-08$ & 16.527 & $5.45 \mathrm{E}-06$ & $1.86 \mathrm{E}-06$ & 0.32533 \\
\hline Arginine and proline metabolism & 8 & 38 & 0.00301 & 5.806 & 0.22873 & 0.028089 & 0.28068 \\
\hline Citrate cycle (TCA cycle) & 6 & 20 & 0.001488 & 6.5105 & 0.11456 & 0.015622 & 0.27512 \\
\hline Pentose phosphate pathway & 3 & 22 & 0.18299 & 1.6984 & 1 & 0.61483 & 0.27226 \\
\hline Purine metabolism & 12 & 65 & 0.000959 & 6.9499 & 0.075743 & 0.013423 & 0.27171 \\
\hline Tyrosine metabolism & 7 & 42 & 0.02008 & 3.908 & 1 & 0.11245 & 0.2369 \\
\hline Pyruvate metabolism & 3 & 22 & 0.18299 & 1.6984 & 1 & 0.61483 & 0.20684 \\
\hline Glycolysis / Gluconeogenesis & 3 & 26 & 0.25592 & 1.3629 & 1 & 0.7962 & 0.20594 \\
\hline Glyoxylate and dicarboxylate metabolism & 7 & 32 & 0.004395 & 5.4272 & 0.32966 & 0.036405 & 0.20371 \\
\hline
\end{tabular}


Figure 5

bioRxiv preprint doi: https://doi.org/10.1101/2020.04.21.054361; this version posted March 11, 2021. The copyright holder for this preprint

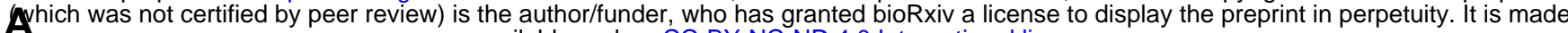
available under aCC-BY-NC-ND 4.0 International license.

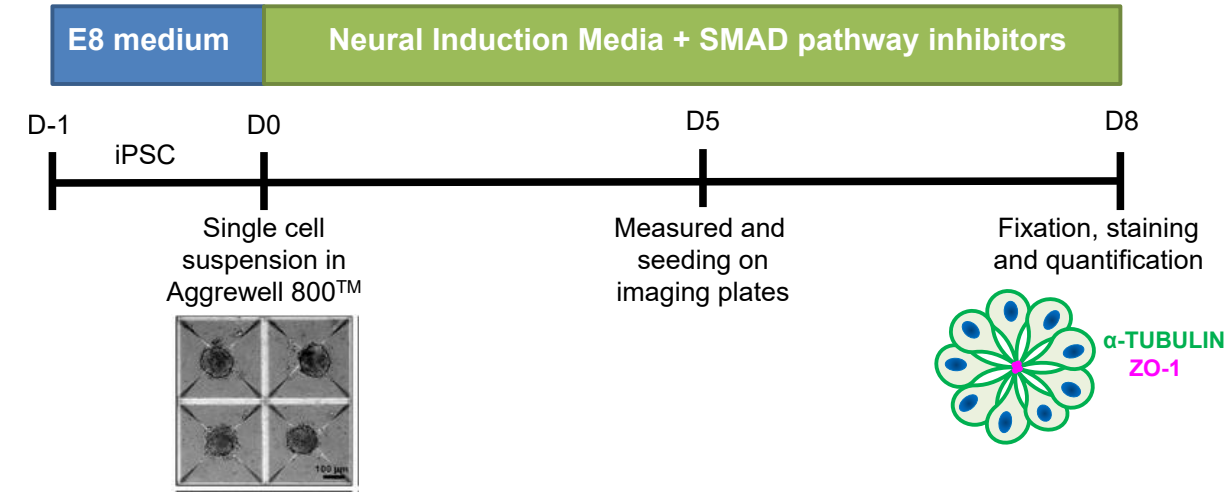

B
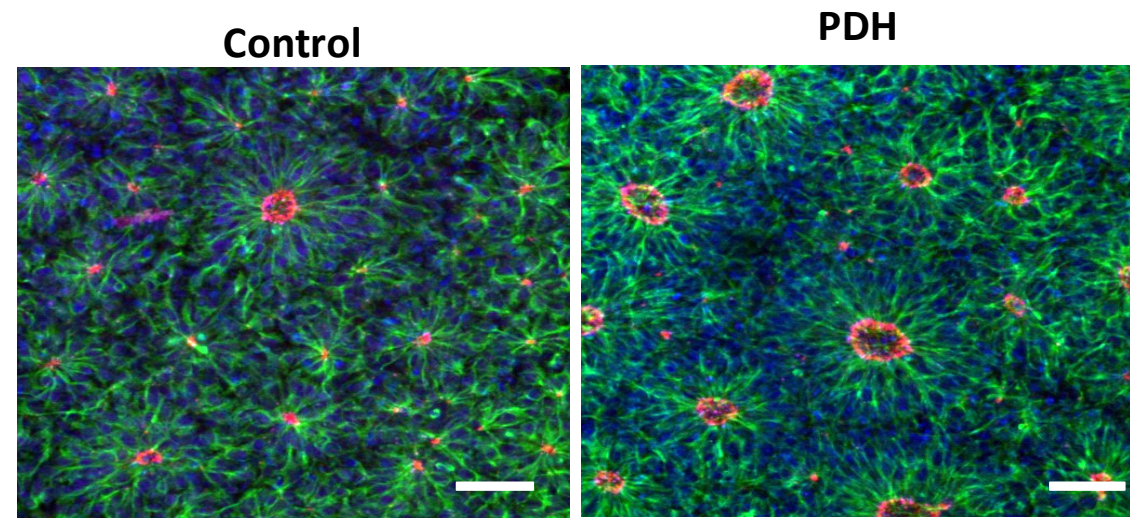

$\alpha-T U B U L I N$

CDK5RAP2

Nucle i

ZO-1
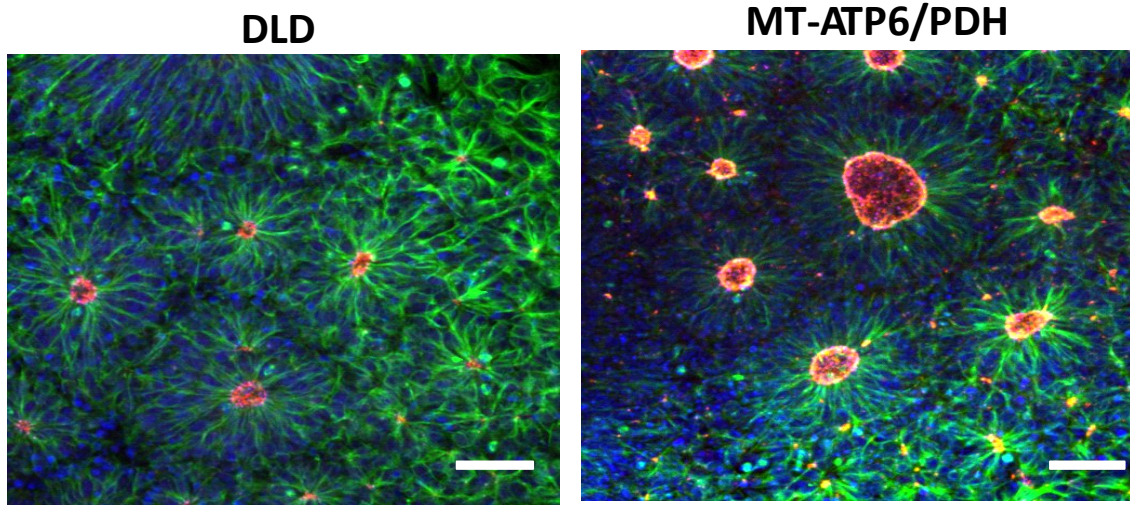

$\alpha$-TUBULIN

CDK5RAP2

Nucle i

ZO-1

C

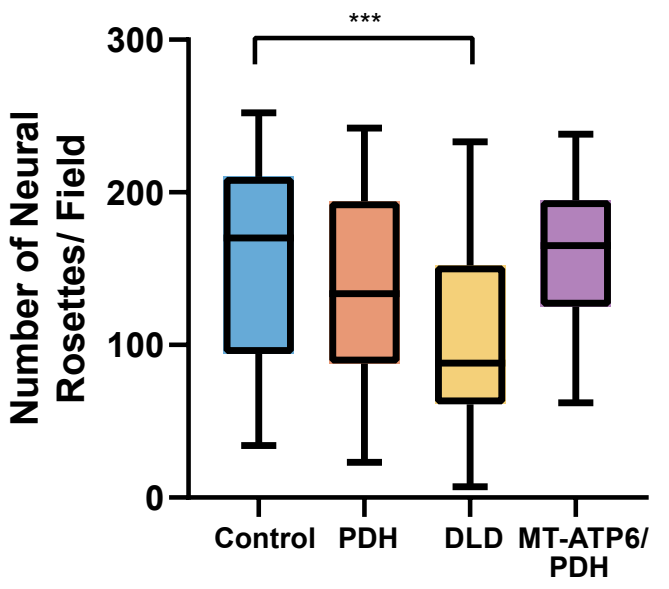

D

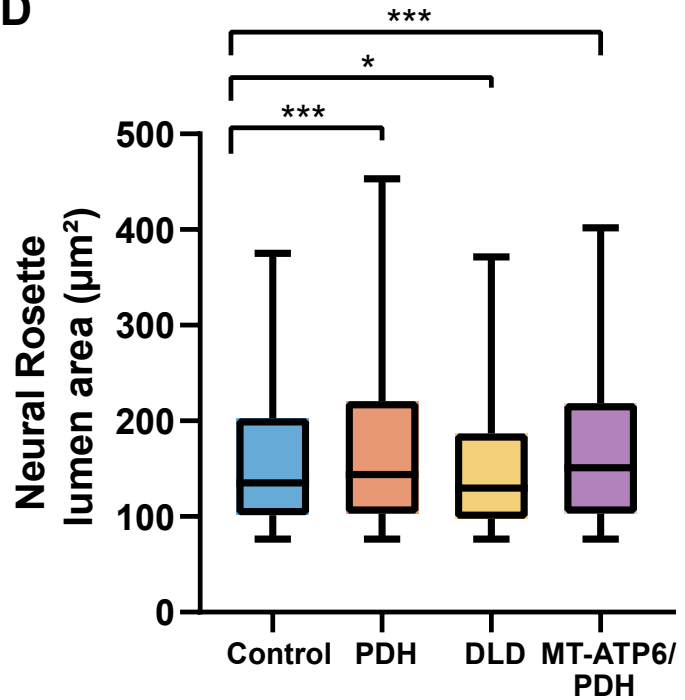


Figure 6

A bioRxiv preprint doi: https://doi.org/10.1101/2020.04.21.054361; this version pos Ed March 11, 2021. The copyright holder for this preprint (which was not certified by peer review) is the author/funder, who has granted bioRxiv a liceense to display the preprint in perpettuity̌t. It is made available under aCC-BY-NC-ND 4.0 International lidense.
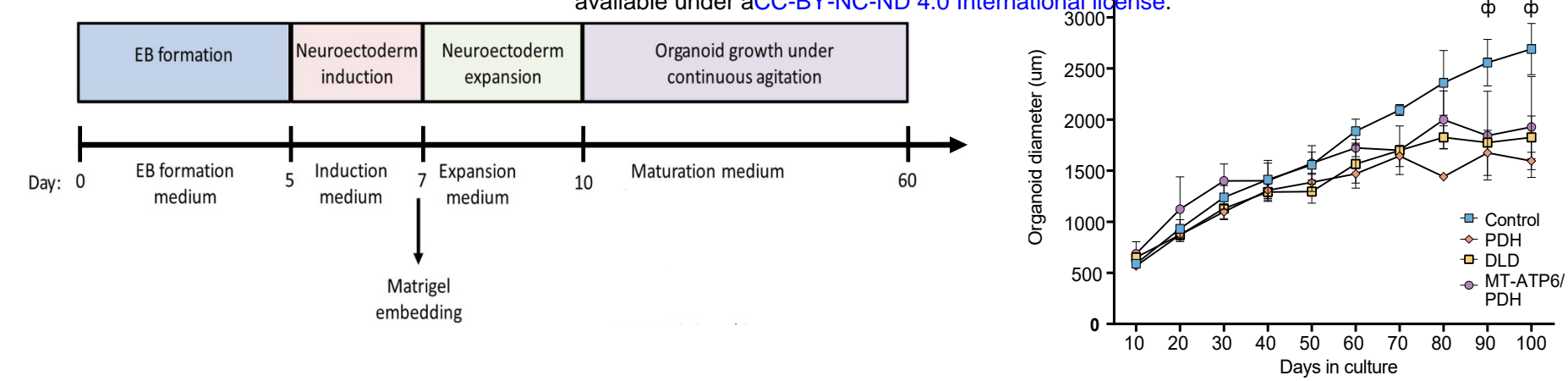

C
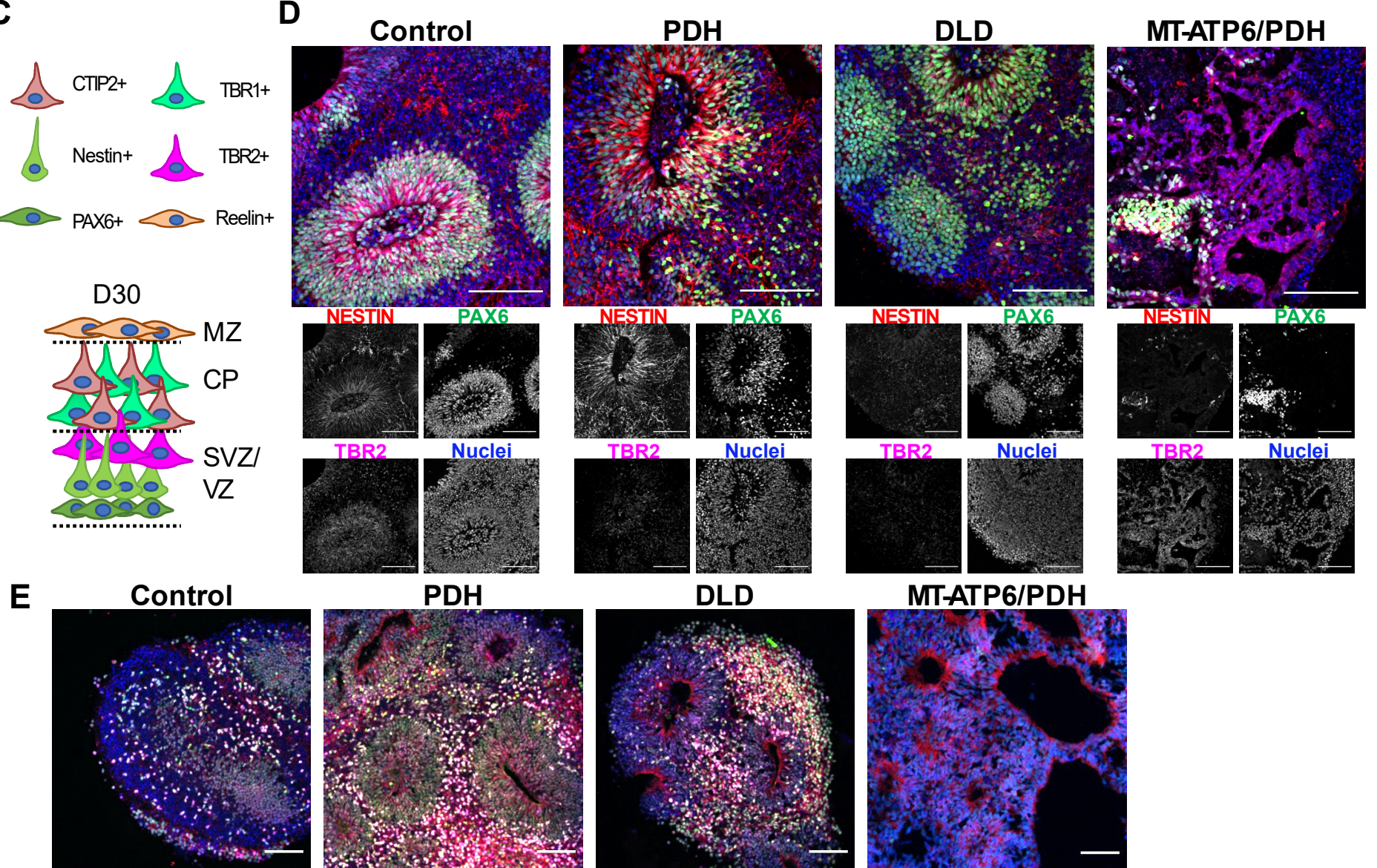

DLD

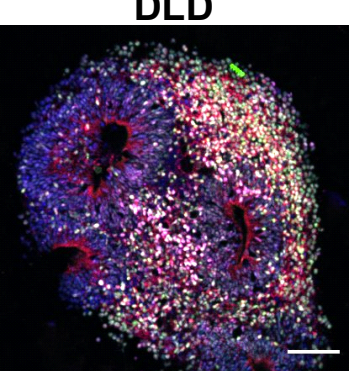

MT-ATP6/PDH
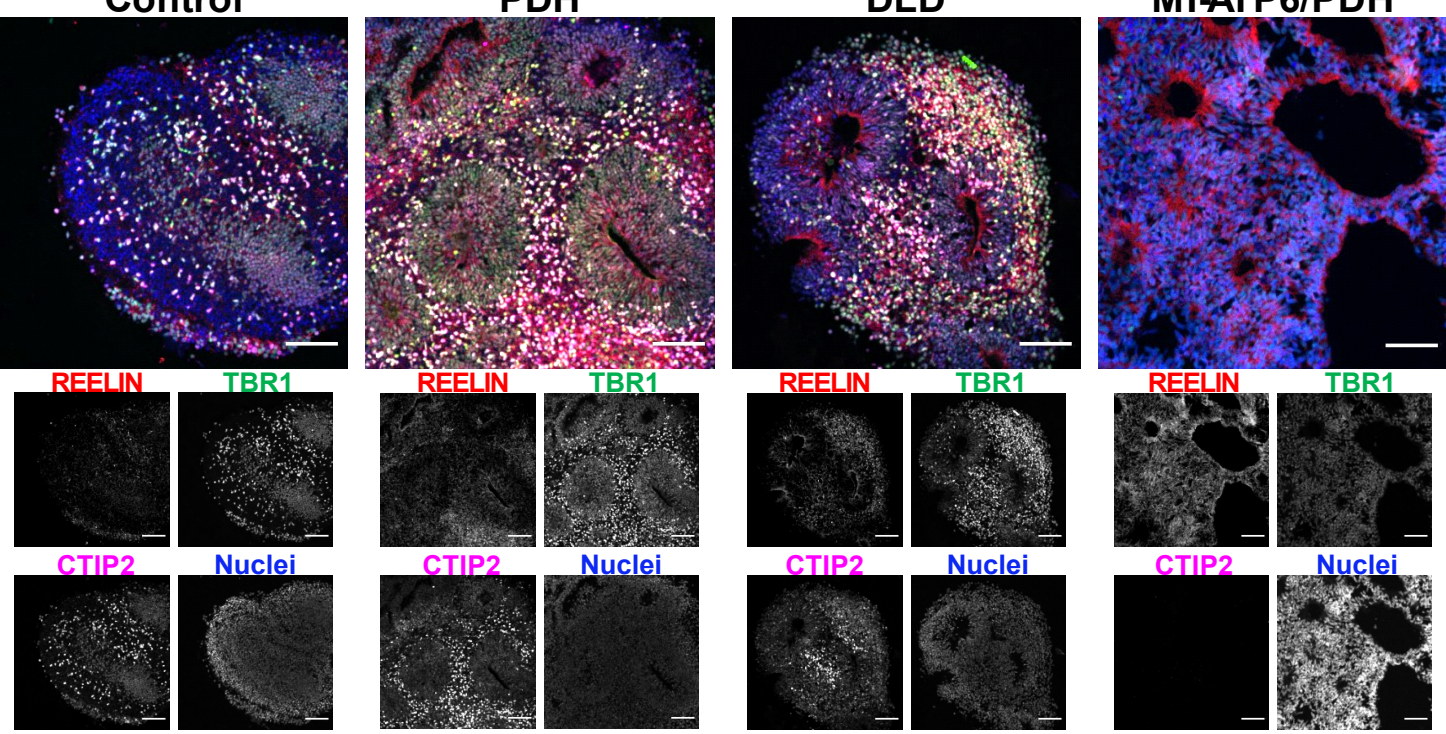

$\mathbf{F}$
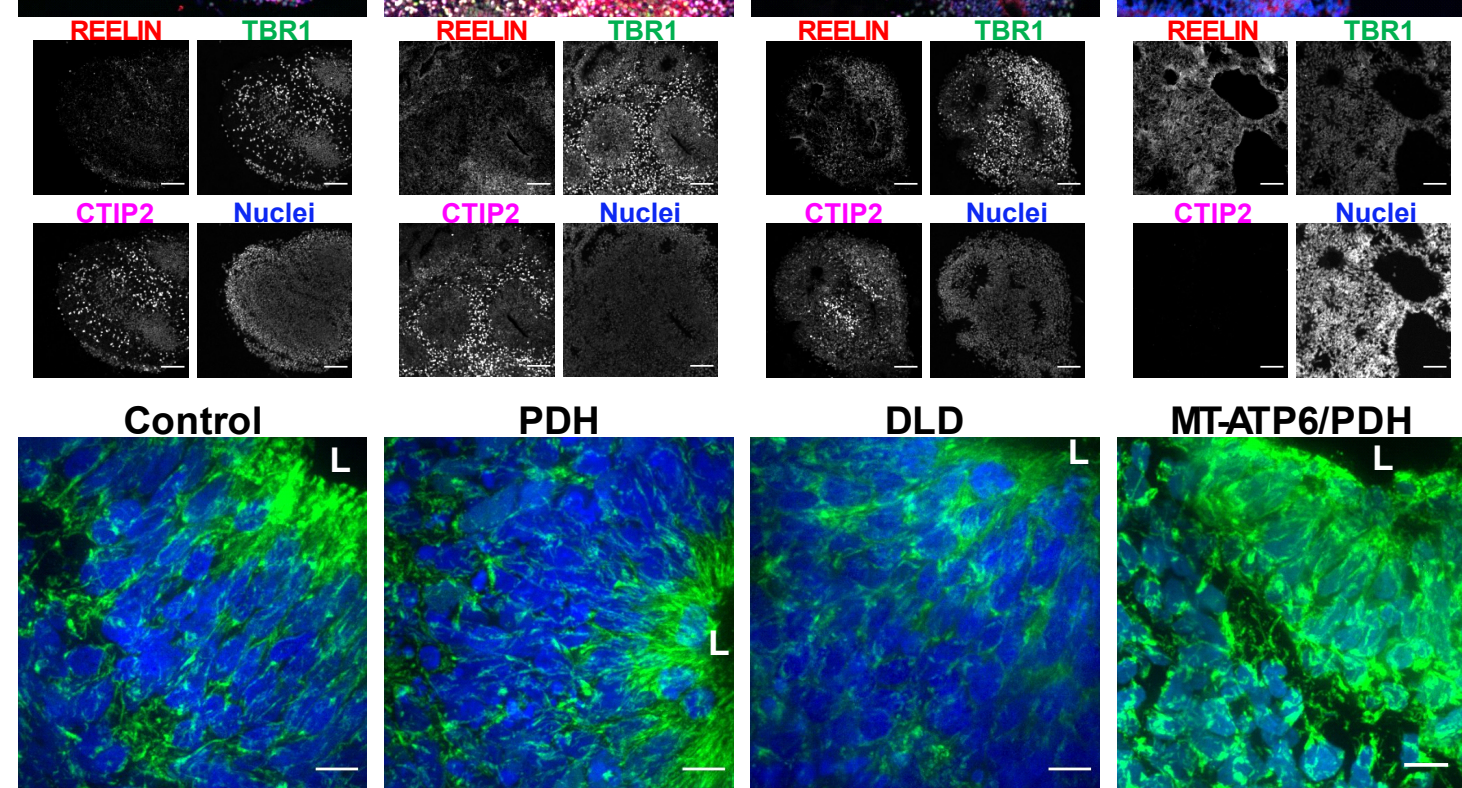

MT-ATP6/PDH
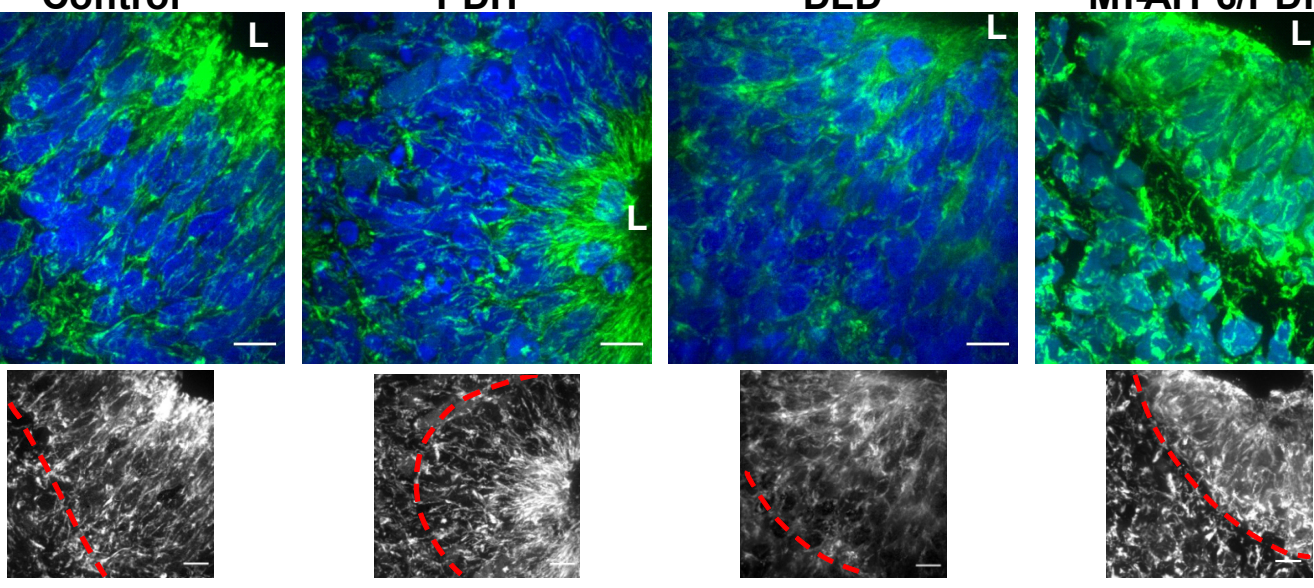
Figure 7

bioRxiv preprint doi: https://doi.org/10.1101/2020.04.21.054361; this version posted March 11, 2021. The copyright holder for this preprint (which was not certified by peer review) is the author/funder, who has granted bioRxiv a license to display the preprint in perpetuity. It is made

A

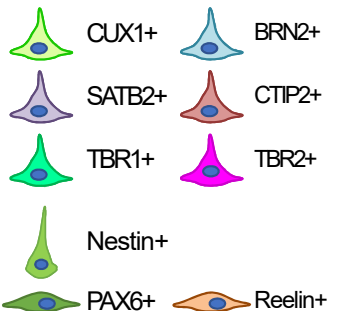

D100

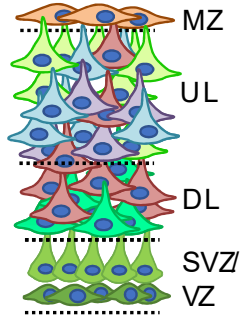

B
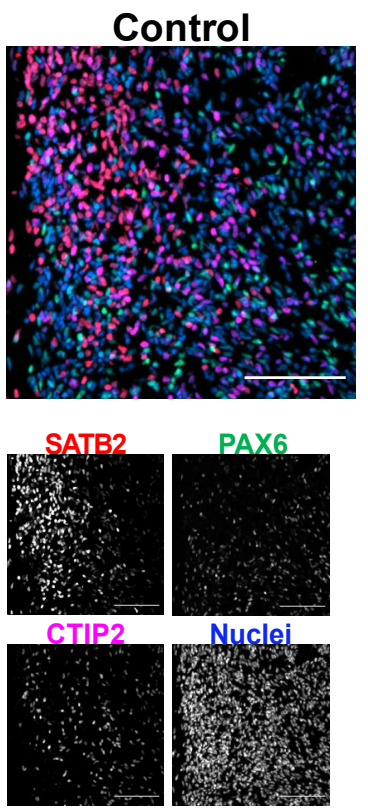
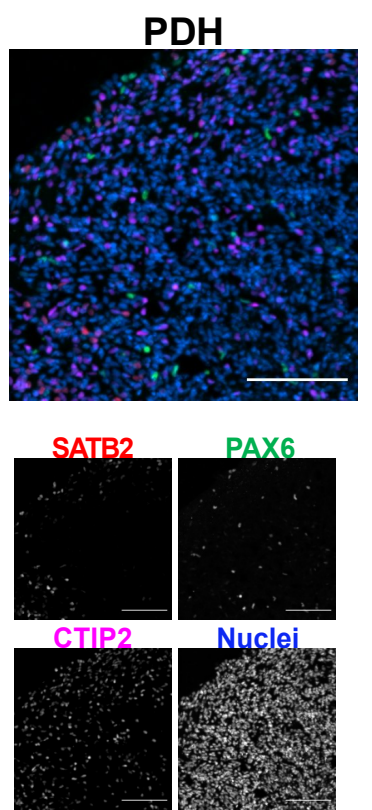
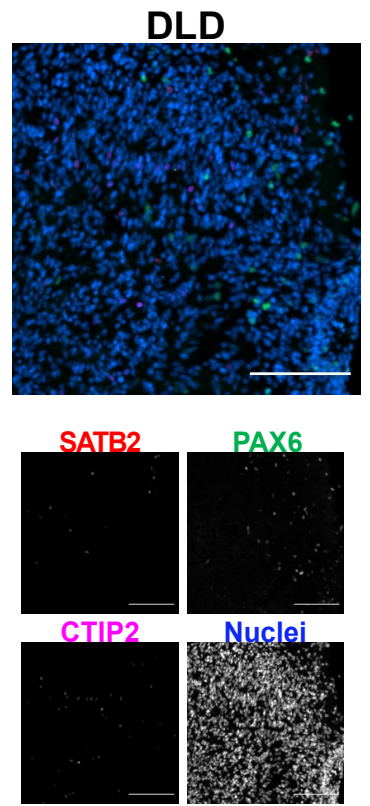

\section{MT-ATP6/PDH}
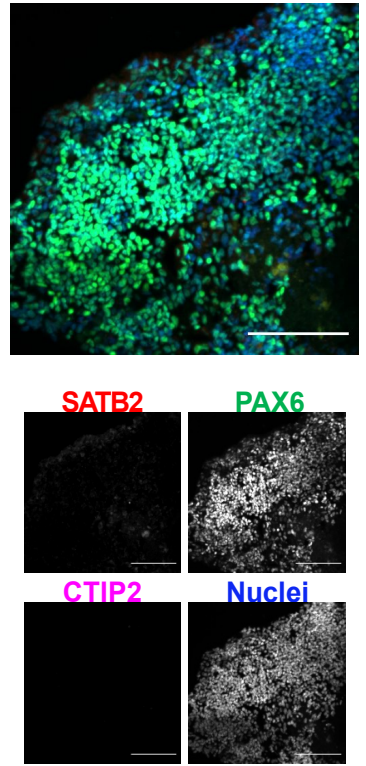

C
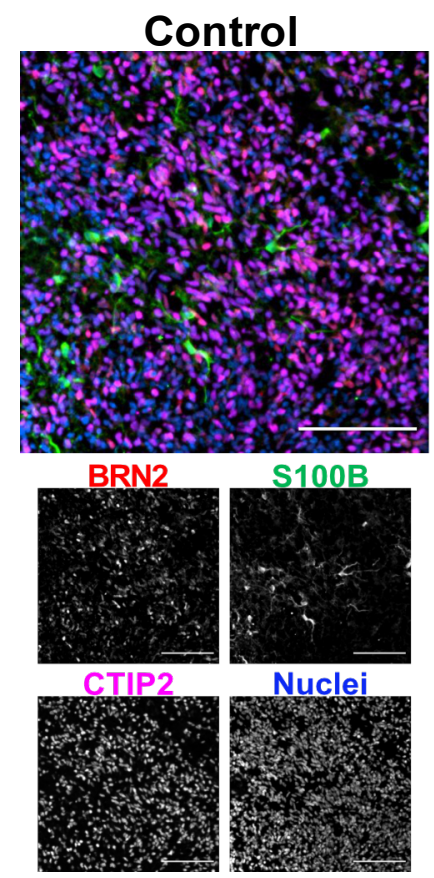

D
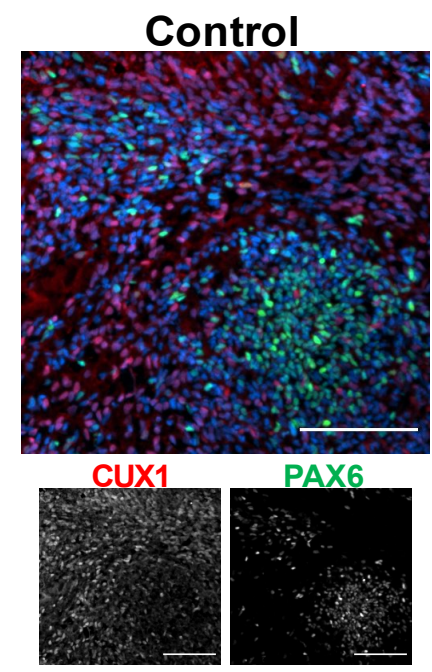
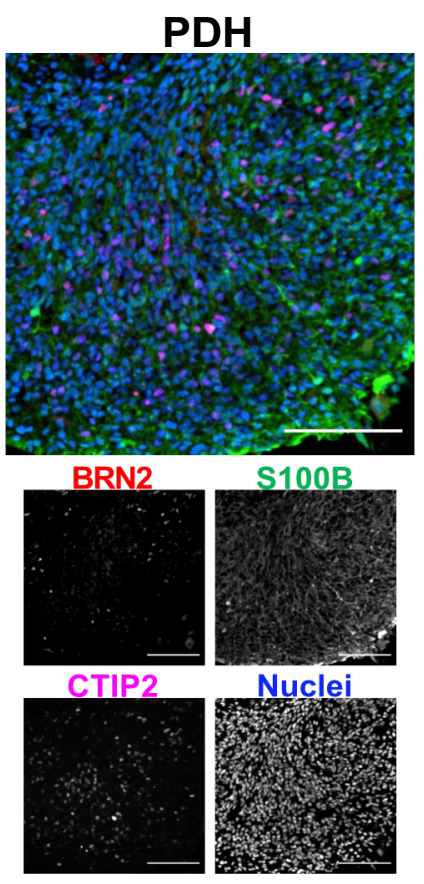

PDH

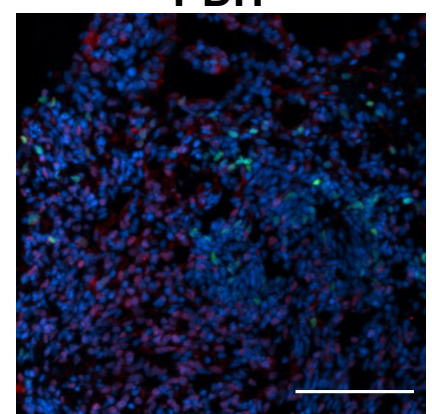

CUX1

PAX6

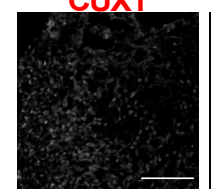

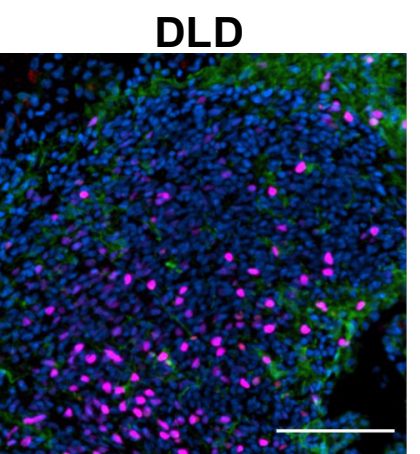
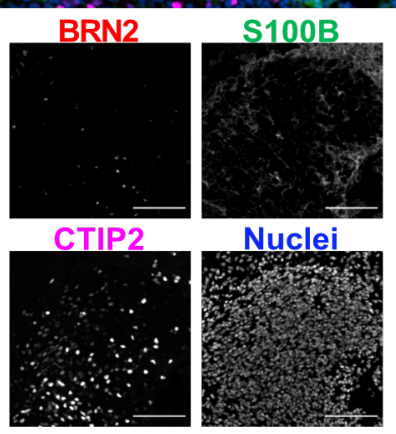

DLD

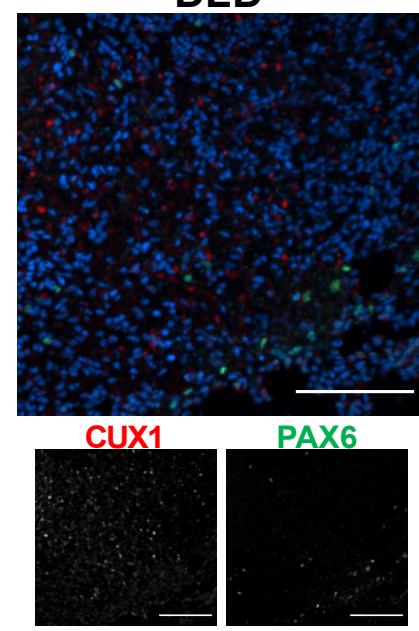

\section{MT-ATP6/PDH}
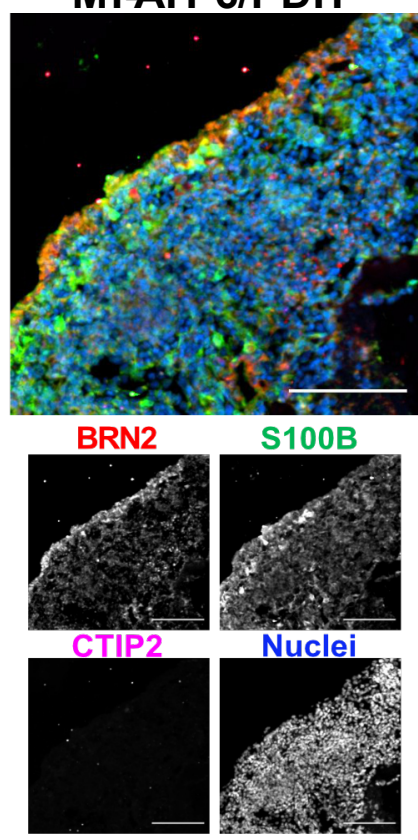

\section{MT-ATP6/PDH}
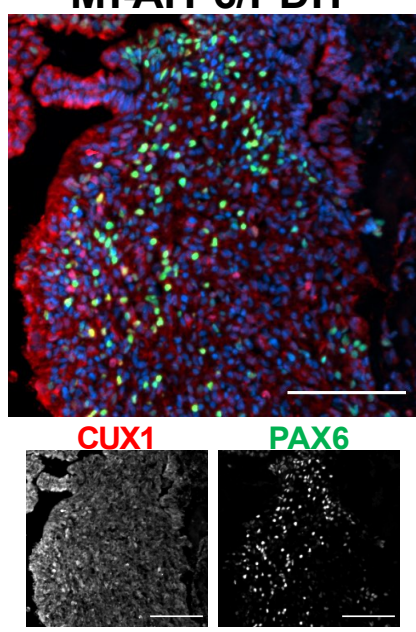